\title{
Propuesta organizacional del área de recreación para la Universidad Estatal a Distancia
}

\section{Organizational Proposal for the Recreation Area of the Universidad Estatal a Distancia}

\author{
Cecilia Enith Romero Barquero \\ Escuela de Educación Física y Deportes \\ Universidad de Costa Rica \\ San José, Costa Rica \\ cenith14@gmail.com
}

Resumen: El estudio consistió en realizar primero una investigación de diagnóstico del área de recreación de la Universidad Estatal a Distancia (UNED), mediante la aplicación de entrevistas al personal encargado del Programa Cultura y Deporte de la institución. A partir de los resultados de dicho diagnóstico, se diseña y presenta una propuesta organizacional, que incluye aspectos administrativos básicos como son: la misión, la visión, objetivos, estructura dentro de la Institución (organigrama), asi como el respectivo reglamento orientado a darle funcionalidad al área de recreación. Es importante destacar que la población estudiantil será la que se beneficie de forma directa con los proyectos que realice el área de recreación, por lo cual esta población se considera en el desarrollo de este proyecto. Para estos efectos, se aplicó un cuestionario al alumnado del Centro Universitario de San José de la UNED, con el objetivo de obtener diferentes criterios y opiniones acerca de las actividades recreativas. Las respuestas que de ahí surgen y de acuerdo con el interés mostrado sirven, por un lado, como base para futuros proyectos recreativos que se deseen poner en práctica en este centro de estudio, específicamente en la sede de San José; por otro lado, son de utilidad para generar mayor evidencia acerca de la necesidad de un área

\section{Introducción}

La presente investigación tuvo la finalidad de analizar el estado del área de recreación en la Universidad Estatal a Distancia (UNED), para determinar si contaba o no con misión, visión, funciones y si estaba contemplada en el reglamento del Programa Cultura y Deporte (PCD) y en el organigrama de la institución. Luego, de acuerdo con los resultados, se dio a la tarea de diseñar una propuesta organizacional con la que se solventen las carencias en el área de recreación. Lo anterior busca fortalecer una de las principales necesidades en la vida de las personas como lo es la recreación. Mathieu (1993) refuerza esta afirmación, al mencionar que la Organización de las Naciones Unidas señala a la recreación como una necesidad básica y la clasifica como sexta en importancia. 
de recreación en la Universidad, lo cual fortalece la justificación de la propuesta y las recomendaciones del presente proyecto. El trabajo establece un precedente de importancia para todas aquellas instituciones que deseen fortalecer o crear un área de recreación, ya que orienta el proceso de cómo hacerlo.

Palabras clave: Propuesta, organigrama, misión, visión, objetivos, reglamento, actividades recreativas, UNED, proyectos recreativos, recreación, estudiantes.

Abstract: The study consisted of a first diagnosis for the recreation area of the Universidad Estatal a Distancia (UNED), by means of the application of interviews to the personnel in charge of the cultural and sports program of the institution. From the results of this diagnosis, an organizational proposal was designed and presented, that included basic administrative aspects like: the mission, the vision, objectives, structure within the institution (organizational chart), as well as the respective regulation oriented to give functionality to the recreation area. It is important to emphasize that the student population will be the one that directly benefits from the projects that the recreation area puts into place. Thus this population is considered important in the development of this project. For these effects, a questionnaire is applied to the UNED students of the San José University Center, with the objective to obtain different criteria and opinions about the recreational activities. The answers that arise from this study show the interests and agreement of the students. It will serve two purposes. It will be used as a basis for future recreational projects, specifically in the San José University Center, and it will generate greater evidence about the necessity of a recreation area in the University, which fortifies the justification of the proposal and the recommendations of the present project. This document establishes a precedent of importance for all those institutions that wish to fortify or create a recreation area, since it orients the process of how to do it.

Key words: Proposal, organization chart, mission, vision, objectives, regulation, recreational activities, UNED, recreational projects, recreation, students.
De acuerdo con Roque (1999), la vida cotidiana se ve afectada por la rutina, las obligaciones y la falta de interés, lo cual llega a provocar tensiones, cansancio, estrés y una serie de situaciones que deben ser atendidas por medio de un proceso que permita la recuperación de las capacidades y las energías perdidas. Dicho proceso está caracterizado por un descanso activo, por la ejecución de actividades diferentes, libremente elegidas y que proporcionan placer. Señala, además este autor, que ese placer se logra por medio de opciones recreativas.

Por lo tanto, el proveer a la población estudiantil de opciones recreativas que le provoquen placer y descanso activo es sumamente necesario; debido a esto, con la aplicación de la propuesta que se desarrolla en este trabajo el estudiantado tendría un mayor acceso a este tipo de actividades, ya que al tener un área de recreación, la institución puede plantear, promover y realizar proyectos recreativos con mayor facilidad, apoyo y seguimiento.

Para dar inicio a dichos proyectos es importante que el primer paso sea el planeamiento para crear una estructura organizacional en el área de recreación de la UNED, la cual deberá adaptarse a las condiciones del alumnado, a los recursos humanos, materiales, normativa y demás aspectos que involucra la institución. Además, es necesario diagnosticar el interés y el gusto por las actividades recreativas que posee la población estudiantil universitaria, ya que el alumnado es el que se beneficiará de forma directa con el área de recreación. En este caso, cuando se hizo el estudio se tomó en cuenta específicamente la población estudiantil de la Sede de San José como un primer paso; sin embargo, es importante que se pueda aplicar a otras sedes para conocer sus intereses, necesidades y gustos específicos, incluso a la misma sede mencionada para tener datos actualizados.

Cabe destacar que la propuesta organizacional que se diseñó en su momento 
y que se presenta hoy en este artículo pretende beneficiar no solo a la UNED y a sus distintas sedes, sino a toda aquella universidad o centro de estudio que desee tener o fortalecer el área de recreación dentro de su institución, ya que al existir una propuesta como esta, sirve de ejemplo a las personas interesadas en establecer áreas similares puesto que las orienta en los procedimientos que necesitan hacer en su afán de mejorar el área de recreación.

Tal es el caso de la misma UNED que, actualmente, establece un área de recreación dentro de su institución y que, a la vez, modificó el nombre del programa que se encargaba de las actividades extra curriculares. El programa se llamaba "Programa Cultura y Deporte" y ahora es llamado "Programa del Arte, Deporte y Recreación”. Según el encargado de la actual área de recreación, el programa está basado en ideologías y metodologías importantes que se desarrollaron en esta propuesta. Incluso, agrega que los planteamientos de la propuesta poseen gran valor para que otras universidades los tomen en cuenta (A. Echeverría, Encargado del área de recreación del Programa Arte, Deporte y Recreación de la UNED, entrevista personal, 8 de octubre de 2010).

\section{Objetivos generales}

A) Diagnosticar el estado organizacional del Programa de Cultura y Deporte (PCD) en la UNED.

B) Diseñar y sugerir una propuesta organizacional en elárea de recreación para la UNED, tendiente a solventar los problemas que se detecten con el diagnóstico.

\section{Objetivos específicos}

A-1) Detectar la misión en el área de recreación del Programa de Cultura y Deporte en la UNED.
A-2) Identificar la visión en el área de recreación del Programa de Cultura y Deporte en la UNED.

A-3) Revisar el reglamento que regula el área de recreación del Programa de Cultura y Deporte en la UNED.

A-4) Identificar si existen funciones específicas para el área recreativa del Programa de Cultura y Deporte en la UNED.

A-5) Determinar los recursos humanos, materiales, instalaciones y presupuesto con los que cuenta el Programa de Cultura y Deporte en la UNED.

A-6) Identificar las actividades y proyectos recreativos que fomenta el Programa de Cultura y Deporte en la UNED.

A-7) Definir el interés del estudiantado con respecto a las actividades recreativas.

\section{Revisión de la literatura}

A continuación se presentan datos administrativos, organizativos $y$ reglamentarios de la UNED, institución en la cual se realizó este proyecto, con el fin de ubicarse en el contexto en el que se realizó la investigación y conocer su problemática. Además, se aclaran conceptos y clasificaciones importantes que intervienen en el campo de la recreación, tales como tiempo libre, actividades recreativas, formatos y áreas recreativas.

\section{Información de la UNED}

\section{Origen y Centros universitarios}

La UNED fue fundada el 22 de febrero de 1977 por la ley número 6044, con la finalidad de satisfacer las demandas de la educación superior y solventar los problemas que las otras universidades estatales (UCR, ITCR y UNA) no podían resolver. Además, se creó para resguardar el principio de igualdad de oportunidades y democratización de la enseñanza en la 
sociedad costarricense. Está conformada por treinta y dos centros universitarios en todo el país (Aguilar y Meza, 1992).

\section{Estructura organizativa}

De acuerdo con el artículo 7 de la Ley de Creación de la UNED (Costa Rica. Asamblea Legislativa, 1977), la Universidad está dirigida por un Consejo Universitario, integrado en conformidad con el Estatuto Orgánico.

\section{Misión de la UNED}

La Universidad Estatal a Distancia (UNED) es una institución de carácter público que goza de autonomía. Su misión es ofrecer educación superior a todos los sectores de la población, especialmente a aquellos que por razones económicas, sociales, geográficas, culturales, etarias, de discapacidad o de género, requieren oportunidades para una inserción real y equitativa en la sociedad.

Para ello hace uso de los diversos medios tecnológicos que permiten la interactividad, el aprendizaje independiente y una formación humanista, crítica, creativa y de compromiso con la sociedad y el medio ambiente.

La UNED se compromete con la excelencia académica, el desarrollo de la cultura, la ciencia, el arte y los derechos humanos para la construcción de una sociedad justa y una cultura de paz (Universidad Estatal a Distancia [UNED]. Rectoría, s.f.-a).

\section{Visión de la UNED}

La UNED será líder en los procesos de enseñanza y aprendizaje a distancia que emplean de manera apropiada y mediados pedagógicamente, tecnologías y otros medios de comunicación social.
Formará personas para pensar y actuar de manera crítica, creativa y autónoma, que así logre desempeñarse con éxito en el contexto auto-instruccional. Promoverá para ello la búsqueda continua de la excelencia y la exigencia académica en sus quehaceres fundamentales: docencia, investigación, extensión y producción de materiales didácticos. Esto para alcanzar los niveles educativos superiores deseados en condiciones de calidad, pertinencia y equidad, acordes con las demandas de los diversos grupos de la sociedad costarricense.

$\mathrm{Su}$ función académica será conceptuada, esencialmente, como una función de creación, reacción, transmisión y democratización del conocimiento.

Participará de manera protagónica en el desarrollo del país teniendo como meta insertar al graduado en su medio social para que busque formas de convivencia solidarias y tolerantes, el fortalecimiento y ampliación de la democracia y, el respeto al medio ambiente (UNED. Rectoría, s.f.-c).

\section{Programa Cultura y Deporte}

Este programa surgió en 1983 con el nombre de Actividades Extracurriculares, gracias al esfuerzo de la trabajadora social Ana Cecilia Murillo. Con el inicio de FECUNDE (Federación Costarricense Universitaria de Deportes), la UNED empezó a promocionar el deporte. En la segunda edición de los JUNCOS, la Universidad participó con algunos grupos, para lo cual recibió ayuda de otros centros de enseñanza superior. Con el paso del tiempo, el programa cambió su nombre y reforzó aún más sus proyectos, en especial los deportivos y artísticos (J. Jiménez, Coordinador del Programa de Divulgación Académica de la UNED, comunicación personal, 20 de febrero de 2006).

El Programa Cultura y Deporte (PCD) no está dividido por áreas, solo existe una persona coordinadora del programa que 
se encarga de las gestiones organizativas y administrativas delos proyectosyactividades deportivas, culturales y recreativas que realiza la institución, principalmente para el estudiantado. Esto debido a que existe, según G. Rojas (Coordinador del Programa Cultura y Deporte de la UNED, comunicación personal, 7 de diciembre de 2005), una directriz de la Vicerrectoría Ejecutiva que establece que sea esa población y no el personal administrativo ni el docente los beneficiados.

Además de esto, existe otro programa que se encarga de atender a esas poblaciones. "El PCD es pequeño y no puede tener una gran cobertura" (G. Rojas, Coordinador del Programa Cultura y Deporte de la UNED, comunicación personal, 7 de diciembre de 2005).

\section{Normativa para los grupos culturales y deportivos}

El PCD cuenta únicamente con la Normativa para los Grupos Culturales y Deportivos, cuyo propósito es regular aquellas disposiciones de los diferentes grupos de estudiantes que, individual o colectivamente, participen en actividades de proyección institucional, tanto en los ámbitos cultural como educativo.

El artículo II de esta normativa menciona los tres tipos de grupos que existen dentro de la organización del PCD:

a) Grupos permanentes. De acuerdo con la Normativa para los Grupos Culturales y Deportivos (Universidad Estatal a Distancia. Oficina de Bienestar Estudiantil, Programa Cultura y Deporte, 1999, pp. 3-4), se definen como:

Estudiantes que individual o colectivamente representan a la UNED por periodos de un año o más, que se mantengan ensayando o entrenando, que cuentan con director o entrenador y tengan control de asistencia establecido por el Programa de Actividades Culturales y Deportivas de la Oficina de Bienestar
Estudiantil. Estos estudiantes gozarán de beca B durante el tiempo que se encuentren participando en estos grupos, siempre y cuando cumplan con los requisitos académicos que se les exige, de acuerdo al artículo 21 del reglamento de becas a estudiantes de la UNED, el cual se aplica cuatrimestralmente.

Este tipo de beca consiste en la exención del $100 \%$ de la tarifa única y de otros aranceles establecidos por servicios académicos al estudiantado, a criterio del Consejo de Becas de Estudiantes.

b) Grupos No permanentes, a estos pertenecen:

Estudiantes que individual o colectivamente se agrupan para participar en una actividad específica previo aval del Programa de Actividades Culturales y Deportivas. Estos estudiantes gozarán de categoría de beca $\mathrm{E}$ una única vez en el periodo académico posterior a que se haya dado su participación.

Con esta beca, se logra una exención del $25 \%$ de la tarifa única y de otros aranceles establecidos por servicios académicos al estudiantado.

c) Grupos recreativos, estos son:

Estudiantes que participan en forma permanente y no tienen como objetivo la participación competitiva. Sin embargo este tipo de grupos cuentan con proyección comunal y dentro de los mismos Centros universitarios.

Los estudiantes que participan en estos grupos, al igual que los otros, deben asistir en forma permanente y se encuentran bajo la dirección de un instructor; por esta razón pueden contar con la categoría de beca $B$ de manera que se les estimule el esfuerzo que realizan si se dan las condiciones que se solicitan para los grupos permanentes.

\section{Conceptos generales}

\section{Recreación y tiempo libre}

"La recreación es un conjunto de actividades agradables y divertidas, realizadas durante el tiempo libre y que promueven el desarrollo integral de las personas" (Salazar, 2007, p. 5). Ese tiempo libre del que se habla, la autora lo define como "la porción de tiempo no dedicada al 
trabajo, a responsabilidades relacionadas con el trabajo, a formas de cuido personal, o a obligaciones familiares y sociales" (p. 2). Por su parte, Roque (1999) agrega que el tiempo libre ofrece a las personas la posibilidad de elegir, libremente y sin ninguna presión, actividades que les interesen, motiven y gusten.

La recreación, además de realizarse en el tiempo libre, se caracteriza porque se organiza dentro del sistema de educación no formal; es decir, consiste en actividades planeadas, pero su realización no conlleva a la obtención de un grado académico. La selección y participación se hacen de manera voluntaria en dichas actividades (Salazar, 2007).

\section{Trabajo y estudio frente a tiempo libre $y$ recreación}

El proceso académico está muy relacionado con el trabajo, ya que las personas buscan prepararse académicamente de la mejor manera con el propósito de tener mejores empleos. Muestra de ello es que algunos de los países asiáticos cuentan con los índices de jornada laboral y de estudio más altos a nivel mundial. De acuerdo con Stevenson y Stigler (1999), en las escuelas asiáticas la jornada escolar es más larga y cada año lectivo tiene más días. En el caso de las escuelas básicas de China y Japón, el año escolar tiene 240 días de clases, las vacaciones son más breves y distribuidas a lo largo del año.

Otra relación del trabajo con el proceso académico se debe a la competencia laboral, ya que las personas buscan prepararse aún más. Los títulos que certifican a las personas para determinado trabajo se hacen cada vez más necesarios. El artículo de la Conferencia Internacional de Trabajo (Organización Internacional de Trabajo, 2005) señala que en las regiones subdesarrolladas y en algunos países industrializados, las personas que trabajan y tienen una escasa remuneración y calificación se enfrentan a una elevada probabilidad de encarar jornadas prolongadas, ya que deben luchar por conseguir suficiente trabajo para obtener ingresos dignos.

Lograr un nivel superior de estudio puede brindar ciertas ventajas, motivo por el que más personas incursionan en la educación superior. Las universidades, año con año, aumentan la cantidad de estudiantes que ingresan en sus centros. En el caso de Costa Rica, de acuerdo con el Ministerio de Planificación Nacional y Política Económica [MIDEPLAN] y el Sistema de Indicadores sobre Desarrollo Sostenible [SIDES] (2005), el número de estudiantes que ha ingresado en las universidades ha ido en incremento, de 59.947 en el año 1999 a 69.721 en el 2004.

Sin embargo, el hecho de avanzar en los diferentes grados académicos también implica un aumento en las horas de estudio. Por ejemplo, no es comparable el tiempo invertido en la escuela primaria con el de la universidad. Esto produce indirectamente ciertas consecuencias, como la reducción del tiempo para realizar otro tipo de actividades, entre ellas las recreativas. Al respecto, Salazar (1997) indica en un estudio realizado con estudiantes universitarios que una de las principales causas por la cual las personas no realizan actividades recreativas es por la falta de tiempo.

\section{Importancia de la recreación en la educación de las personas}

La recreación tiene un propósito intrínseco que va más allá de la participación; fortalece valores, principios, creencias y todos aquellos aspectos que procuran el crecimiento integral de la persona y de la sociedad. Al respecto, Hernández y Gallardo (1994), mencionan que la recreación significa, actualmente, la necesidad del ser humano de realizar una actividad vital que constituya un complemento a su formación.

La recreación se puede relacionar con los grados académicos, Kraus (1990) 
menciona que las personas con mayor nivel educativo tienden a involucrarse más ampliamente e intensamente en una variedad de formas de recreación. Aquellas personas con educación universitaria, según el autor, participan más frecuentemente en actividades al aire libre, que quienes tienen solo educación secundaria.

En los centros educativos, la recreación cumple un papel fundamental. Por ejemplo, en la Universidad Nacional Autónoma de México, Dirección General de Actividades Deportivas y Recreativas (1996) declara que el deporte y la recreación representan una importante alternativa para sus estudiantes, ya que aprovechan el tiempo libre de una manera sana y consiguen otros beneficios, como obtener experiencia y aprendizaje en la búsqueda de la autosuperación, el triunfo y la identidad que, de acuerdo con sus impresiones, son elementos de gran valía, tanto en la faceta profesional como social.

Esto ya que al participar en actividades recreativas las personas se divierten sanamente. Al respecto, Salazar (2007) destaca que los participantes se benefician en distintos ámbitos como el físico, psicológico, cognitivo, social, emocional y espiritual, logrando consecuencias positivas, en contraste con la diversión negativa que podría dañar a alguien. Esta diversión negativa consiste, según Curtis y Russell, (citados por Salazar, 2007), en actividades y pasatiempos que realizan personas jóvenes y adultas en el tiempo que no dedican al trabajo o estudio, y que la sociedad no ubica dentro de sus parámetros como buenas o saludables, ya que sus consecuencias son negativas.

\section{Actividades recreativas}

Las actividades recreativas son aquellas que se efectúan en el tiempo libre, se seleccionan y se participa de ellas de manera voluntaria $y$ que causan consecuencias positivas en sus participantes. La participación va a depender de varias causas, como por ejemplo: los diferentes gustos, conocimientos, cantidad de tiempo libre, recursos económicos, entre otras razones, que posean las personas (Salazar, 2007).

Incluso, las actividades recreativas pueden variar según el género. Un ejemplo de ello es el estudio realizado por Águila (2005), quien menciona que las actividades de recreación en la población universitaria son similares, pero con diferentes niveles de participación. En cuanto al género, el esparcimiento de las jóvenes universitarias es más cultural, involucra más a la pareja, a la familia y está más asociado al cultivo de relaciones sociales. En cambio, en los hombres universitarios el esparcimiento está más relacionado con las nuevas tecnologías, los juegos, la compañía de los amigos, hacer actividades deportivas y ver programas relacionados con el deporte.

Salazar (2007) señala también que existen diferentes tipos de actividades recreativas; entre ellas se encuentran: a) deportes, juegos, actividades físicas; b) actividades artísticas (música, artes plásticas, danza, drama); c) actividades sociales (fiestas, reuniones sociales, festivales, actividades socializadoras, relacionadas con la comida, visitas, conversaciones, clubes, descubrimiento de talentos); d) actividades al aire libre (deportes y actividades relacionados con la naturaleza, conservación y estudios del ambiente); e) actividades cognoscitivas (redacción, lectura, oratoria, discusión y estudio de temas, actividades con la computadora, juegos pasivos); f) enriquecimiento y actualización personal (clases, cursos, talleres, congresos, seminarios); g) pasatiempos (colección, modelos a escala, otros) y turismo (paseos y excursiones). Salazar agrega que estas actividades se pueden realizar en forma individual, en pequeños o grandes grupos, al aire libre, bajo techo, durante poco tiempo, una sola vez, durante varios años o a lo largo de toda la vida y facilitan que las personas sean más felices y se sientan realizadas. 
Por otra parte, Villalobos (2001) indica que las actividades recreativas se pueden realizar de manera activa cuando se ejecuta la acción o pasiva cuando se observa una de estas actividades.

Pérez (citado por Hernández y Gallardo, 1994) agrega que las actividades recreativas se distinguen por varios aspectos, tales como:

- Todo el mundo debe poder participar sin que la edad, el sexo o el nivel de entrenamiento se conviertan en factores limitadores.

- Las reglas pueden ser creadas o adaptadas por los propios participantes en el mismo lugar.

- Existen posibilidades de opción en cuanto al tipo de actividades, cómo practicarlas, etcétera.

- "Jugar con los demás es más importante que jugar contra los demás". El ganar o perder, elemento agonístico de la práctica, pasa de ser objeto a ser el medio utilizado para divertirse.

La práctica recreativa no descarta el aprendizaje de habilidades, técnicas o actitudes. Aunque no sea su principal objetivo, no debe descartarse el esfuerzo físico. (p. 66)

\section{Formatos recreativos}

Los formatos recreativos son las maneras de ofrecer las actividades recreativas. Se pueden clasificar así: a) grupos y clubes con intereses sociales, b) competenciasyconcursos, c) paseos y excursiones, d) actividades especiales e) educación, f) instalación abierta y g) servicio voluntario (Salazar, 2007). Estos formatos se desarrollan dependiendo de los intereses, necesidades y gustos de la población que desee recibir las actividades recreativas y, por lo tanto, se van a convertir en parte fundamental de la estructura organizativa de un área de recreación, porque según mencionó Salazar, son la forma de ofrecer las distintas actividades que deseen las personas usuarias.

\section{Áreas de trabajo en recreación}

Existe en el mercado varias áreas que se encargan de promover y fomentar la recreación en los distintos sectores de la población. Una de ellas es de vital importancia en este caso, porque es precisamente la que se encarga de desarrollar actividades recreativas en los centros de estudio. Al respecto, Salazar (2007) menciona que existen diferentes áreas como la comunitaria, comercial, terapéutica, laboral, militar, acuática, municipal, privada y, la de interés para este trabajo, la universitaria. Esta área, según la autora:

Se desarrolla en instituciones educativas. Se ocupa por el bienestar de la población estudiantil y de enriquecer su aprendizaje académico. Incluye la programación de deportes, actividades artísticas y actividades relacionadas con los estudios. Proporciona oportunidades para liberar la tensión causada por la carga académica (p. 70).

En esta área, Salazar también señala varias instituciones costarricenses que ofrecen actividades recreativas, tales como la Universidad de Costa Rica (UCR), Universidad Nacional (UNA), Universidad Estatal a Distancia (UNED), Instituto Tecnológico de Costa Rica (ITCR), Escuela de Agricultura de la Región del Trópico Húmedo (EARTH) y universidades privadas.

\section{Metodología}

A continuación se detalla el tipo de investigación, la descripción de las personas que participaron en el estudio, la descripción de los instrumentos que se usaron en este trabajo y los procedimientos que se realizaron antes y durante la propuesta.

\section{Tipo de investigación}

Esta investigación es transeccional descriptiva. De acuerdo con Hernández, Fernández y Baptista (2003), "los diseños de investigación transeccional o transversal recolectan datos en un solo 
momento, en un tiempo único" (p. 270). Además, agregan que uno de los propósitos de estos diseños es describir comunidades, eventos, fenómenos o contextos. Según Ary, (citado por Mathieu, 1993), "una investigación descriptiva permite obtener la información requerida acerca de la situación existente en el momento de la recolección de datos" (p. 77). En este caso, la información recabada fue la relacionada con el área de recreación de la UNED. Best (citado por Ary, Lucy y Asghar, 1984) menciona que la investigación descriptiva se interesa por las condiciones existentes, las prácticas que predominan o las tendencias que están desarrollándose.

\section{Sujetos de estudio}

Para realizar el diagnóstico se trabajó con el personal del PCD y con la población estudiantil de la UNED, de la cual se tomó una muestra de trescientos ochenta y siete estudiantes (387), de los cuales ciento sesenta y nueve (169) eran hombres y doscientas dieciocho (218) eran mujeres. Toda esta población pertenecía al Centro Universitario San José de la UNED. El procedimiento de muestreo fue no probabilístico (por conveniencia y facilidad de acceso a los sujetos).

Para el desarrollo de la propuesta organizacional se trabajó nuevamente con el personal de la Oficina de Bienestar Estudiantil (OBE), específicamente en la elaboración del organigrama, con el personal del PCD y la directora de la OBE. Para la creación de la misión, visión y objetivos, se trabajó con personas de la OBE: la directora, el personal del PCD, del Programa de Becas, del Programa Orientación Estudiantil, con dos trabajadoras sociales y la asesora legal de la UNED. Y para el desarrollo del reglamento, con el personal del PCD, la directora de la OBE y la asesora legal de la UNED.

\section{Instrumentos utilizados en el diagnóstico}

\section{Entrevista para el diagnóstico}

En la entrevista para el diagnóstico se utilizó la entrevista de tipo estructurada. Consistió en realizarle al personal del PCD 13 preguntas abiertas, cuyo propósito era obtener información acerca del estado del área de recreación en la UNED. Fue realizada en la segunda visita que se le hizo al personal. Durante la misma se tomaron apuntes en una bitácora para luego analizarlos de manera cualitativa. Para dicho análisis se seleccionó la información relevante y se agruparon las respuestas que apuntaban al mismo tópico y, luego, estos datos fueron resumidos para poder concluir si el área de recreación del PCD contaba o no con la información solicitada en cada pregunta, o en qué condiciones se encontraba.

El principal aspecto que se trató en las preguntas fue la existencia de una misión, visión, objetivos, reglamento, organigrama, recursos humanos, materiales, presupuesto, centros universitarios que tenían en el área de recreación, programas, proyectos y actividades recreativas, actividades especiales, carreras en las que se incluían cursos relacionados con recreación, grupos deportivos y culturales con los que contaba la institución e instalaciones deportivas o recreativas disponibles, además de cursos obligatorios de actividad artística o deportiva para la población estudiantil.

\section{Cuestionario de actividades recreativas aplicado a estudiantes del Centro Universitario de San José en el diagnóstico}

El cuestionario constaba de cinco preguntas cerradas: las dos primeras solicitaban datos personales (edad y sexo), esto con la intención de considerar no solo las respuestas de toda la población estudiantil, sino conocer también las diferencias según 
el sexo. En cuanto a las tres preguntas restantes, tenían como objetivo conocer el grado de interés de la población estudiantil universitaria hacia las actividades recreativas, para lo cual se consideraba: a la Universidad como ente productor de actividades, las preferencias del alumnado y la importancia de dichas prácticas para el desarrollo integral de las personas.

Las actividades recreativas que conformaban la lista fueron seleccionadas según los recursos humanos, los materiales y el presupuesto con el que contaba la institución. Esto con el propósito de que las actividades que se planteen en futuros proyectos recreativos sean factibles de realizar. El instrumento fue validado por juicio de personas expertas en el tema, y se aplicó en el periodo de matrícula a la población estudiantil del Centro Universitario de San José. La manera de hacerlo fue la siguiente: a medida que iba llegando la población estudiantil, se le entregaba el cuestionario junto con los demás documentos de matrícula, lo completaba y devolvía ese mismo día al personal a cargo de la matrícula.

\section{Procedimientos}

\section{Procedimientos para el diagnóstico}

a) Con la información obtenida en la entrevista del diagnóstico, se hizo un resumen, el cual fue dado al personal del PCD, que lo revisó y corrigió para su respectiva validación. Los datos obtenidos sirvieron posteriormente para redactar la justificación y parte del marco teórico de la propuesta. Además, constituyeron la base de la cual surgió la elaboración de la propuesta.

b) Una vez aplicado el cuestionario, se recogieron los datos y se procedió a su tabulación y análisis; esto se codificó de la siguiente manera:

b-1) Los cuestionarios fueron clasificados en dos grupos, hombres y mujeres. A su vez, en cada grupo se contó a las personas que respondieron que sí y aquellas que dijeron que no querían que la Universidad realizara actividades recreativas dirigidas a la población estudiantil; esto con respecto a la primera pregunta.

b-2) Por facilidad en el procedimiento, se tabuló la pregunta número tres, para la cual se usaron sólo los cuestionarios en los que la respuesta de la primera pregunta fue afirmativa. Para ello, se contó a las personas que respondieron que sí y a aquellas que dijeron que no creían que las actividades recreativas fueran importantes para el desarrollo integral de las personas.

b-3) Después, se tabuló la pregunta número dos, para la cual se utilizaron solamente los cuestionarios en los que la respuesta fue afirmativa a la primera pregunta. Para esta tabulación, el primer paso fue seleccionar las cinco actividades recreativas de mayor interés de cada estudiante, según la preferencia al marcar del número uno al cinco.

b-4) Cada actividad recreativa tenía un código de dos letras, el cual había sido asignado con anterioridad. Dicho código se incorporaba al programa de Excel, luego de la selección antes mencionada.

b-5) En el programa de Excel se hicieron dos tablas según el sexo, en las cuales se ubicó a la población estudiantil, junto con el código de cada una de las cinco actividades recreativas de su interés. Se mantuvo el orden de prioridad, que se definía por los números del uno al cinco. 
b-6) Todas las actividades recreativas eran ubicadas en las casillas de la tabla que se hizo en el programa Excel, con un respectivo puntaje, el cual correspondía al orden de prioridad señalado por la población estudiantil. Las actividades con número uno eran ubicadas en la columna de 5 puntos, la número dos en la columna de 4 puntos, la número tres en la de 3 puntos, la número cuatro en la de 2 puntos y la número cinco en la de 1 punto.

b-7) Se ordenaron alfabéticamente los códigos y se contaron los puntos obtenidos por cada actividad recreativa, en las cinco prioridades.

b-8) Se construyó una tabla con dichos valores, tanto absolutos como relativos. De dicha tabla se hicieron varios gráficos, al igual que para la primera y la tercera pregunta. Los gráficos se realizaron según el sexo, y otros con la población en general.

\section{Procedimientos para la propuesta}

El procedimiento que siguió la investigadora para la elaboración de la propuesta fue el siguiente:

a) Se analizaron los resultados obtenidos en el diagnóstico, tanto de la entrevista y la revisión de bibliografía como del cuestionario.

b) Se determinó la estructura para la propuesta.

c) Se buscó y amplió la información acerca de los temas de la propuesta.

d) Se realizó un taller con el personal del PCD, que consistió en conceptos generales acerca de recreación, tiempo libre, diversiones positiva y negativa, beneficios, barreras, actividades $\mathrm{y}$ formatos recreativos, con el fin de generar y unificar ideas, que iban a servir para la elaboración de la propuesta.

\section{Elaboración del organigrama}

e) Se hizo una reunión con el personal del PCD, en la cual se analizó el organigrama que regía a la Universidad y se confeccionó una posible estructura, en la que se incluyó el área de recreación.

f) Se entregó a la directora de la OBE la propuesta del organigrama, quien la analizó y aprobó.

\section{Elaboración de la misión}

g) Se hizo un taller dirigido al personal de PCD, en el que se explicó el concepto de misión, se dieron ejemplos de algunas misiones de instituciones y se inició, por parte del personal y en conjunto con la investigadora, la elaboración de una misión para el PCD de la UNED.

h) Se mejoró la propuesta de la misión por medio del trabajo en conjunto con el personal del PCD.

i) Se solicitó al personal del PCD el borrador de la propuesta, la cual se analizó y se le consideraron posibles cambios. Una vez realizado esto, fue nuevamente enviada al personal de la OBE, específicamente a la directora, al personal del PCD, al del Programa de Becas, al del Programa Orientación Estudiantil, a dos trabajadoras sociales y, por último, a la asesora legal de la UNED, quienes la revisaron y devolvieron con algunas observaciones.

j) Se tomaron en cuenta dichas observaciones y se incluyeron en la propuesta. 
k) Se devolvió la propuesta al mismo personal de la OBE, que analizó el documento y dio el visto bueno a la propuesta, lo cual estableció el final de este proceso, en el que se logró elaborar una misión para el PCD.

\section{Elaboración de la visión}

l) Se realizó un taller dirigido al personal del PCD, en el cual se expuso el concepto de visión, se dieron ejemplos de algunas visiones de instituciones $y$, finalmente, el personal y la investigadora iniciaron juntos la elaboración de una visión para el PCD de la UNED.

m) Se continuó con la elaboración de la visión para el PCD, de la misma manera como se hizo con la creación de la misión.

\section{Elaboración de objetivos}

n) Se realizó una reunión con el personal del PCD, durante la cual se dieron ejemplos de objetivos, que sirvieron para la elaboración de unos dirigidos al área deportiva, el área artística y la recreativa. Este proceso fue realizado por el personal del PCD y por la investigadora.

o) Se mejoró la propuesta de los objetivos por medio de la observaciones realizadas por el personal del PCD y estas fueron entregadas a la investigadora.

p) Se revisó la propuesta de los objetivos para las áreas, se hicieron algunas correcciones y se devolvió al personal.

q) Se redactó una nueva propuesta de objetivos de las áreas, en la que se incluyeron las recomendaciones dadas por la investigadora.

r) Se revisó el documento de los objetivos, con las correcciones hechas y se envió a la directora de la OBE y a la asesora legal de la UNED, quienes estudiaron la propuesta y realizaron algunas observaciones. Estas se analizaron e incorporaron al documento.

s) Se revisó la propuesta por parte de la directora y la asesora legal y a la vez dieron el visto bueno al diseño de los objetivos para las áreas.

\section{Elaboración del reglamento}

t) Se hizo una reunión con el personal del PCD, en la cual se explicaron aspectos acerca del reglamento, se dieron ejemplos de otras instituciones, se analizó la normativa vigente del PCD y fue iniciada, por parte del personal del programa y de la investigadora, la elaboración de un reglamento, en el cual el área de recreación fue tomada en cuenta.

u) Se solicitó al personal del PCD la propuesta del reglamento para analizarla aun más, se le hicieron algunas modificaciones y fue entregada nuevamente al personal del PCD.

v) Se revisaron las observaciones de la investigadora por parte del personal del PCD, el cual las aceptó e incorporó al documento. Este fue dado luego a la asesora legal de la UNED, quien ofreció algunas sugerencias, que fueron tomadas en cuenta e incorporadas a la propuesta.

w) Una vez incluidas las correcciones, se le entregó el documento a la directora de la OBE, quien lo revisó y aceptó. Con lo anterior, se dio por terminada la confección del reglamento.

x) Se redactó el informe final de la propuesta.

\section{Resultados y discusión}

A continuación se presentan los resultados obtenidos en el diagnóstico, los 
cuales fueron alcanzados por medio de la entrevista y del cuestionario.

\section{Resultados y discusión obtenidos de la Entrevista}

La entrevista fue realizada al personal del PCD de la UNED. A continuación, se presenta la información proporcionada por el coordinador del PCD (G. Rojas, Coordinador del Programa Cultura y Deporte de la UNED, entrevista personal, 16 de noviembre de 2005).

Área de recreación

Según la información brindada en la entrevista, el área de recreación no existía como tal en la UNED; por lo tanto, esta área no se encontraba en ningún organigrama de la institución. Sólo se realizaban algunas actividades recreativas coordinadas por la persona encargada del PCD, ya que la mayor proyección de este programa estaba dirigida al deporte de representación de la institución y al área de "cultura", así que era en este programa (PCD) donde se debería incluir el área de recreación. Por esto, esta información reflejaba la necesidad de establecer un área de recreación que proveyera proyectos recreativos bien estructurados y planificados y no actividades aisladas. La participación en programas recreativos provee de satisfacción en varios aspectos como disfrutar individualmente o en grupo, obtener relajación, salud, autonomía, entre otros (Rossman, 1983). Morales (1994) señala también que "la recreación es utilizada hoy día como un medio para darle uso positivo al tiempo libre, y que participar en un plan recreativo ofrece al individuo un desarrollo integral que le permite desenvolverse mejor dentro del grupo en que vive" (p. 21).

Por lo tanto, al no existir proyectos recreativos, la población estudiantil de la UNED estaba privada de recibir los beneficios que, según Salazar (2007), se obtienen por medio de las actividades recreativas.
Sin embargo, es importante señalar que el personal del PCD, en el momento en el que se realizó este estudio, tenía en proceso el diseño de una propuesta mediante la cual se pretendía modificar la estructura de la UNED; esto al dividir este programa en tres áreas, que serían: deporte representativo, arte y recreación. Lo anterior era de interés para el desarrollo de las áreas y para que la comunidad universitaria tuviera la posibilidad de disfrutar y de participar en una mayor variedad de actividades y competencias.

La propuesta que desarrolló la investigadora a partir del estudio fue un aporte importante para los propósitos de la propuesta del personal del PCD, porque en ella se crearon varios aspectos administrativos básicos que eran necesarios para la nueva estructura que se pretendía formar. La propuesta de la investigadora también fue relevante porque fortalecía el área de recreación de la UNED, la cual serviría como complemento que acompañaría al área deportiva y al área artística.

\section{Estructura organizacional}

Por otra parte, al no existir el área de recreación, tampoco existían elementos organizativos como misión, visión, objetivos, o bien, encontrar el área en el organigrama de la institución. Inclusive el PCD, como entidad de la UNED, tampoco contaba con misión ni visión.

La sugerencia de estos elementos es la base para la propuesta que se desarrolló en este trabajo.

Por lo tanto, la creación de esta propuesta generó la estructura organizativa para el área de recreación, la cual, si se lograra conformar, sería de gran beneficio, ya que los procedimientos administrativos y organizativos vendrían a ser más factibles para la elaboración y puesta en práctica de proyectos recreativos sostenibles. Al mismo tiempo, el personal de la UNED tendría 
una guía formal que unificaría criterios en el momento de realizar dichas acciones, de modo que se lograría coherencia y homogeneidad entre sí.

Tampoco se encontró un reglamento específico del área de recreación, o algún reglamento que mencionara el tema de la recreación. Sólo se tenía la Normativa para los Grupos Culturales y Deportivos, que pertenecía al PCD, cuyo objetivo era regular aquellas disposiciones de los diferentes grupos de estudiantes que, individual o colectivamente, participaban en actividades de proyección institucional, tanto cultural como educativa.

Sin embargo, de acuerdo con la información recolectada en la entrevista, los grupos recreativos no habían tenido mucha proyección ni tampoco habían sido funcionales, porque eran grupos que recibían beca pero no representaban a la Universidad en ninguna actividad externa a la institución. Además, solo se había conformado un grupo de fútbol en Liberia, otro en Turrialba y uno de aeróbicos en Alajuela, pero no habían sido constantes.

Por otra parte, el artículo III de la normativa señalaba que la Coordinación de Actividades Culturales y Deportivas era la instancia técnica encargada de establecer la categorización de estos grupos y la responsable de que se cumplieran los requisitos establecidos en la normativa.

En cuanto a las funciones, solamente existían las señaladas en el perfil ocupacional que planteaba la Oficina de Recursos Humanos de la Universidad para la persona encargada del PCD, las cuales incluían la organización, la administración y la supervisión de los proyectos y actividades, llevados a cabo en el área deportiva y en la cultural, así como de las pocas realizadas en recreación, entre otras responsabilidades.

\section{Recursos humanos y materiales del PCD}

En lo que se refería a recursos humanos, se halló a una persona coordinadora del PCD; además, dicho programa contaba con quince personas instructoras: diez en los grupos deportivos y cinco en los grupos culturales. Se esperaba que en un corto plazo aumentara el personal a veintitrés: siete en los grupos culturales y dieciséis en los deportivos. También se pretendía abrir dos plazas más, una para el área cultural (artística) y otra para recreación. Además, existía la posibilidad de dar becas a estudiantes que fungieran como líderes en el área de recreación. Asimismo, al establecerse las tres áreas, se trabajaría de manera complementaria entre las personas instructoras, líderes y los proyectos por realizar. Esta disposición del programa era de gran apoyo para la promoción, creación y fortalecimiento de áreas como la recreativa.

Por otro lado, no se encontraron materiales en bodega; los almacenados eran los deportivos, como bolas, conos y mallas, entre otros, o vestuario y utilería de los grupos culturales, los cuales se hallaban bajo el poder y manejo de cada uno de los equipos o representaciones universitarias. Sin embargo, sí existía la posibilidad de comprar material y contar con los servicios de la editorial, audiovisuales y vídeoconferencias.

El promedio del presupuesto que se tenía para implementos era alrededor de dos millones y medio de colones; para viáticos, tres millones y medio de colones; y para uso de instalaciones, un millón. Sin embargo, estas cifras eran anuales y correspondían a toda la Oficina de Bienestar Estudiantil, no solo al PCD.

En cuanto a instalaciones, la UNED solo poseía un gimnasio que se encontraba en el Centro Universitario de San José, el cual estaba techado, con iluminación y gradería.

La UNED contaba con 32 centros universitarios en todo el país. En ninguno de ellos poseía un área de recreación establecida. Sí se habían realizado algunas actividades recreativas, pero no se les había dado continuidad. Sin embargo, algunos sí tenían grupos deportivos representativos como ajedrez, tenis de mesa, atletismo, 
fútbol, fútbol sala, voleibol y resistencia. En el área cultural, existían grupos de baile folklórico y de popular.

\section{Actividades y Grupos recreativos}

Tal y como se mencionó antes, la UNED tenía varios grupos deportivos y culturales que, de acuerdo con lo señalado por el personal del PCD, podrían ayudar en los proyectos recreativos que se llegaran a realizar por medio de su personal, el uso de implementos y el desarrollo de actividades en común.

En cuanto a las actividades especiales (no académicas) que realizaba la Universidad, sóloexistía unTorneoDeportivo Estudiantil llevado a cabo anualmente, con la intención de seleccionar a los equipos que representarían a la Universidad en competencias como JUNCOS. El torneo tenía una duración de dos a tres días y en él participaban disciplinas como fútbol, en la rama masculina, fútbol sala femenino y masculino, así como voleibol femenino. Además, se realizaba un Festival Cultural. En ambas actividades se intentaba incorporar a la población de los diferentes centros universitarios; sin embargo, esto no siempre se lograba.

También existía la Semana Cultural, pero esta estaba dirigida al personal docente $\mathrm{y}$ al administrativo y no era organizada por el PCD; este programa sólo colaboraba en algunos aspectos.

Sin embargo, la UNED no contaba con grupos recreativos, en los cuales las personas que no podían formar parte de determinada disciplina competitiva $o$ representativa tuvieran la oportunidad de integrarse, sin que sintieran presión por competir por un lugar en el grupo, o frustración si no lograban ser aceptados en este. Loy (1975) hace referencia a lo anterior, al decir que:

En las actividades recreativas el hombre puede expresar las partes frustradas de su vida pues le dan la oportunidad de crear o vivir valores que compensen la insatisfacción producida por lo que quiso ser o hacer, y no pudo... Una recreación adecuada puede ayudar a evitar los síntomas patológicos ante la frustración, pues la emoción reprimida tendrá una salida normal a través de una actividad creadora. (p. 30)

De acuerdo con el personal del PCD, los grupos recreativos permitirían que la población que participara en ellos no se preocupara por factores como no tener tiempo o no contar con los recursos indispensables para asistir a los entrenamientos, ensayos, presentaciones y competencias. Lo anterior podría ser explicado por lo que manifiesta Salvador (citado por Gómez y Ruiz, 2003), quien manifiesta que en la Universidad de Valencia se produjo un notable incremento en la demanda de las actividades físico-recreativas con respecto a las de competición, por parte del alumnado. Considera que esto pudo suceder debido a que las actividades físico-recreativas no necesitan de instalaciones muy elaboradas ni amplias; al contrario, existe la necesidad de promover actividades en las que con menos espacio participe mayor número de estudiantes. Otra razón por la cual las actividades competitivas fueron menos solicitadas fue porque demandaban mucho tiempo y la falta de este era una característica de la población estudiantil, debido a la extensión de los programas y a la poca flexibilidad de horarios. Por último, la curiosidad que despertaron ciertas formas de hacer ejercicio fue otra de las causas por las que se escogieron las actividades físico-recreativas.

\section{Cursos con énfasis en recreación}

Otro factor que reafirmó la falta del campo de recreación en la UNED, fue que en ningún plan de estudios de las carreras que ofrecía la Universidad se solicitaba materias que involucraran recrearse. Solamente al alumnado de Ciencias de la Educación se le exigía llevar cursos de 
actividades deportivas para la población infantil. Además, la universidad no contemplaba dentro del plan de estudios de su estudiantado cursos de actividad deportiva o artística como requisito, lo cual sí sucede en otras universidades públicas. Esta ausencia provocaba mayor desconocimiento de dicho campo, porque significaba que la institución no contaba con especialistas en el tema, los cuales podrían dar importantes aportes al área de recreación o incentivar su apertura.

A pesar de las circunstancias adversas y de acuerdo con la información ofrecida por el personal del PCD de la Universidad, el programa disponía de ciertos recursos humanos, económicos y materiales que apoyaban la apertura del área recreativa.

En resumen, con la información obtenida se observó la falta de una estructura organizacional en el área de recreación, pues no se contaba con misión, visión, objetivos, reglamento y funciones. Además, el área de recreación tampoco se encontró en el organigrama de la institución. La carencia de estos aspectos organizacionales evidenció la necesidad de crear el área recreativa.

\section{Resultados y discusión obtenidos del Cuestionario}

De acuerdo con el cuestionario aplicado a la población estudiantil del Centro Universitario de San José de la UNED, se encontraron los siguientes resultados en cada una de las preguntas.

\section{Datos personales}

La primera parte del instrumento solicitaba datos personales como edad y sexo. Esta última variable con mayor importancia, ya que se dividieron las respuestas según el sexo. Se halló que, de los trescientos ochenta y siete (387) estudiantes que respondieron el cuestionario, 44\% eran hombres y $56 \%$ eran mujeres.

\section{Interés del estudiantado en las actividades recreativas}

El siguiente gráfico muestra el alto grado de interés del alumnado ante la posibilidad de que se realizaran actividades recreativas en su universidad.

Interés en que se realizaran actividades recreativas, para el estudiantado, en la Sede de San José de la Universidad Estatal a Distancia

Enero 2006

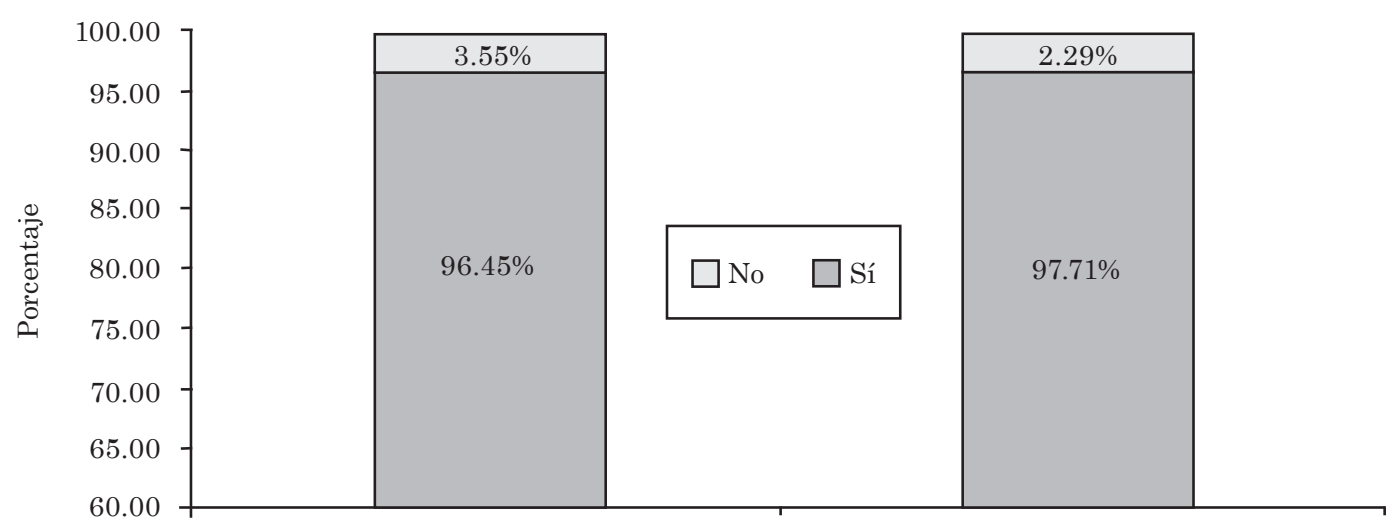


Por lo tanto, el resultado obtenido de la pregunta número uno refleja que el 96,45\% del sexo masculino (163 hombres) contestó que sí le interesaba que la Universidad organizara actividades recreativas para la población estudiantil y solo el 3,55\% (6 hombres) dijo que no.

En cuanto al sexo femenino, el 97,71\% (213 mujeres) contestó que sí le interesaba y solo el 2,29\% (5 mujeres) dijo que no tenía interés. Por consiguiente, hubo un total de trescientos setenta y seis (376) personas $(97,16 \%)$ que respondió que sí y once (11) personas $(2,84 \%)$ que dijeron que no les interesaba que la Universidad ofreciera actividades recreativas dirigidas a la población estudiantil.

Estas respuestas fortalecen la justificación de la propuesta de este trabajo y de las intenciones de abrir el área recreativa, ya que la población directamente implicada, el alumnado, deseaba que se realizaran actividades recreativas.

\section{Actividades recreativas de mayor interés entre la población estudiantil}

Se determinó también el tipo de actividad recreativa que resultaba más atractiva para el estudiantado de la sede de San José, se analizó, por un lado, la escogencia de los hombres y por otro, la de las mujeres. También se hizo el análisis tomando en cuenta ambos sexos.

A continuación, se presenta el gráfico acerca de la preferencia de los hombres estudiantes del Centro Universitario de San José en la UNED con respecto a las actividades recreativas.

Gráfico 2

Actividades recreativas de mayor preferencia entre los hombres estudiantes de la Universidad Estatal a Distancia en el Centro Universitario de San José Enero del 2006

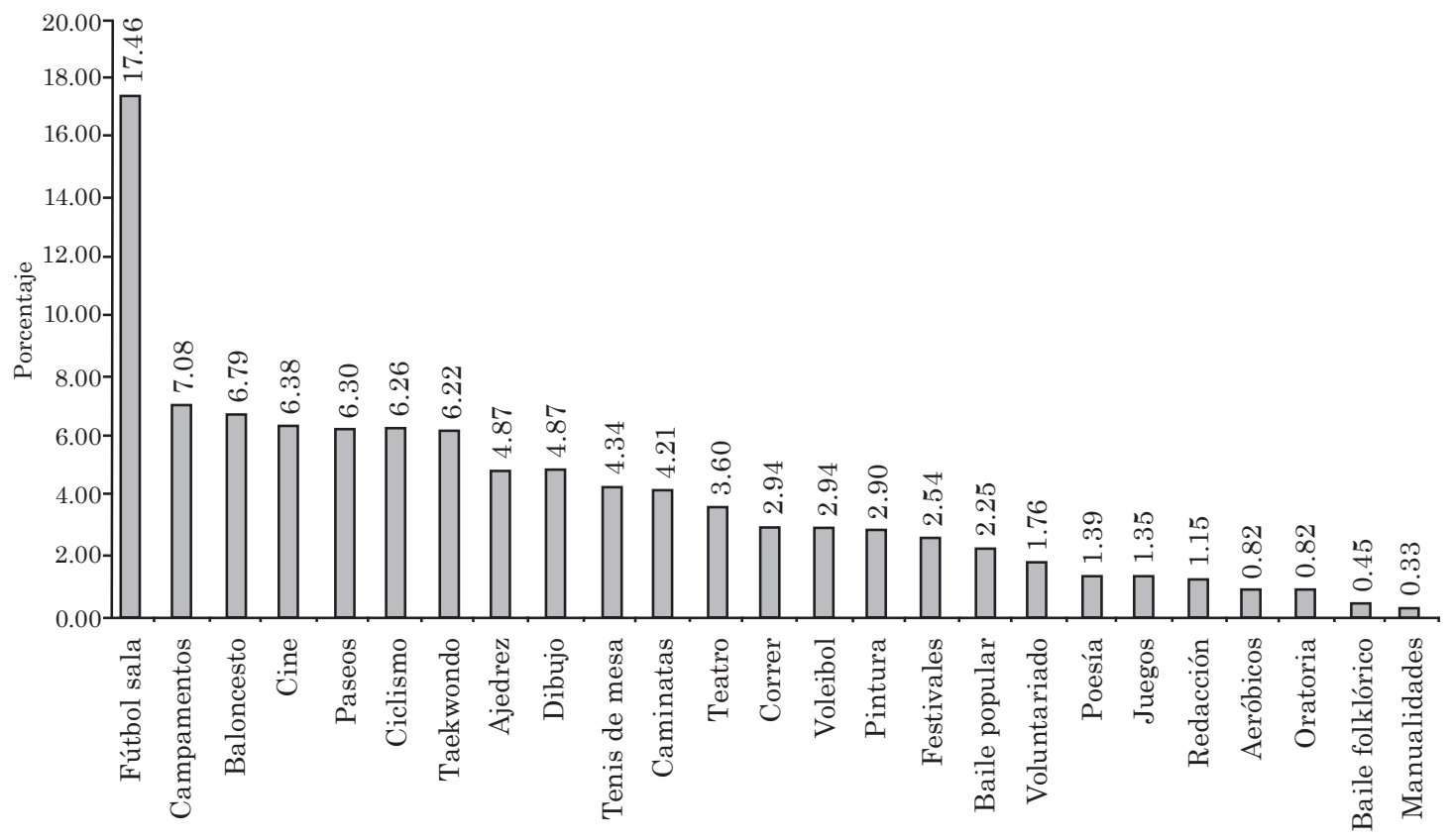

Actividades recreativas 
Por lo tanto, en la pregunta número dos del cuestionario, en cuanto a las actividades recreativas de mayor interés para los hombres estudiantes, los resultados demostraron que, en orden de prioridad, fútbol sala, campamentos, baloncesto, cine y paseos fueron las más aclamadas.

El siguiente gráfico es acerca de las actividades recreativas de mayor interés para las mujeres estudiantes del Centro Universitario de San José en la UNED.

Gráfico 3

Actividades recreativas de mayor preferencia entre las mujeres estudiantes de la Universidad Estatal a Distancia en el Centro Universitario de San José Enero del 2006

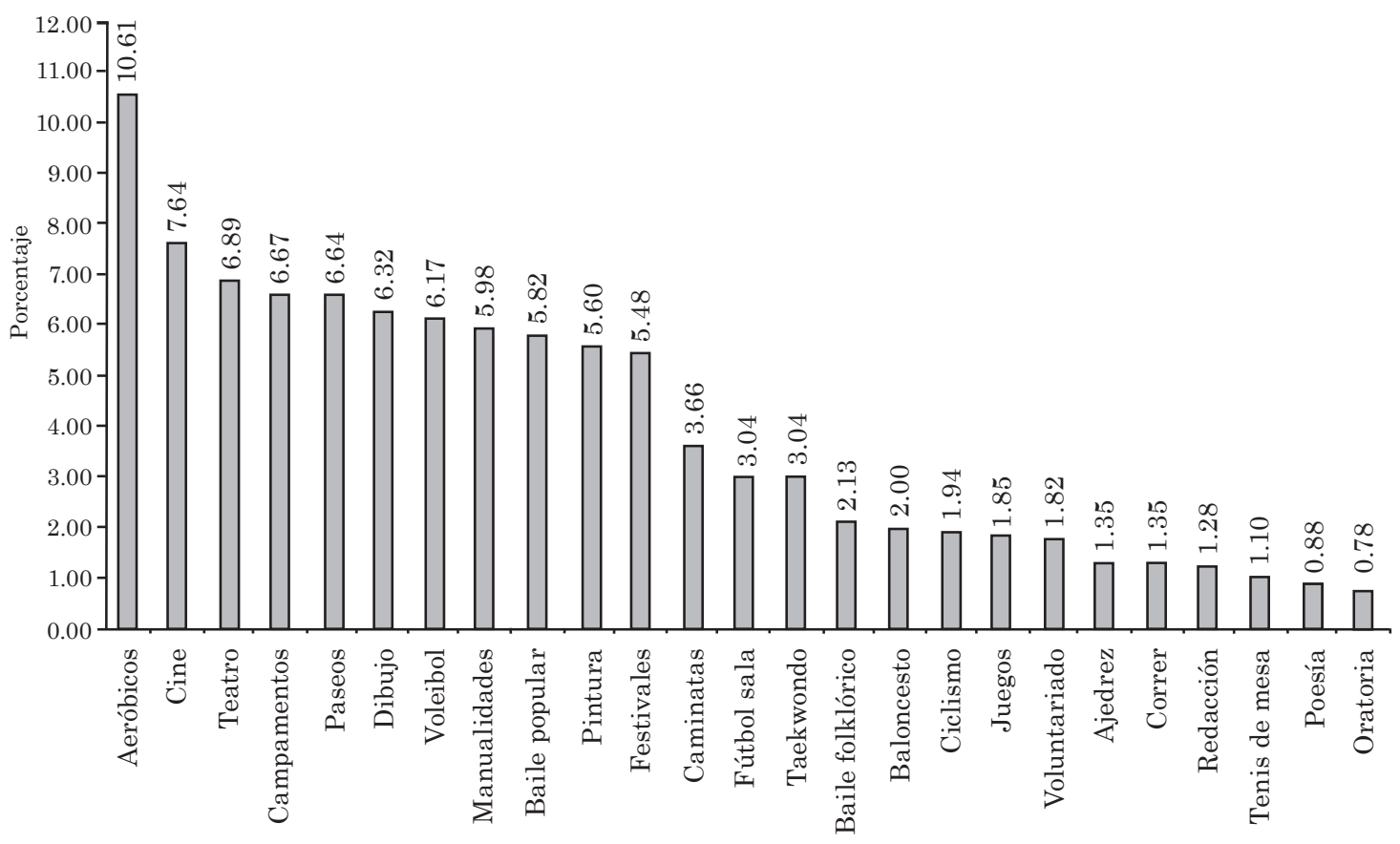

Actividades recreativas

Fuente: Elaboración propia a partir del cuestionario de actividades recreativas, UNED, enero 2006.

Es así como, en el caso de las mujeres, los datos demostraron que aeróbicos, cine, teatro, campamentos y paseos fueron las más gustadas.

El gráfico 4 señala las actividades recreativas más gustadas por la población estudiantil, tanto por hombres como mujeres, del Centro Universitario de San José en la UNED.

Estas actividades, que fueron destacadas por el estudiantado, se pueden convertir en un punto de referencia para futuros proyectos recreativos que se deseen desarrollar en el Centro Universitario de San José de la UNED.

Los resultados obtenidos en el diagnóstico de este trabajo son similares a los reportados en otros estudios, lo cual apoya la promoción de este tipo de actividades. Por ejemplo, Gamboa y Montero (citados por Alvarado, 2000) estudiaron el tiempo libre del personal de la UNA y encontraron 


\section{Gráfico 4}

Actividades recreativas de mayor preferencia entre la población estudiantil total de la Universidad Estatal a Distancia en el Centro Universitario de San José Enero del 2006

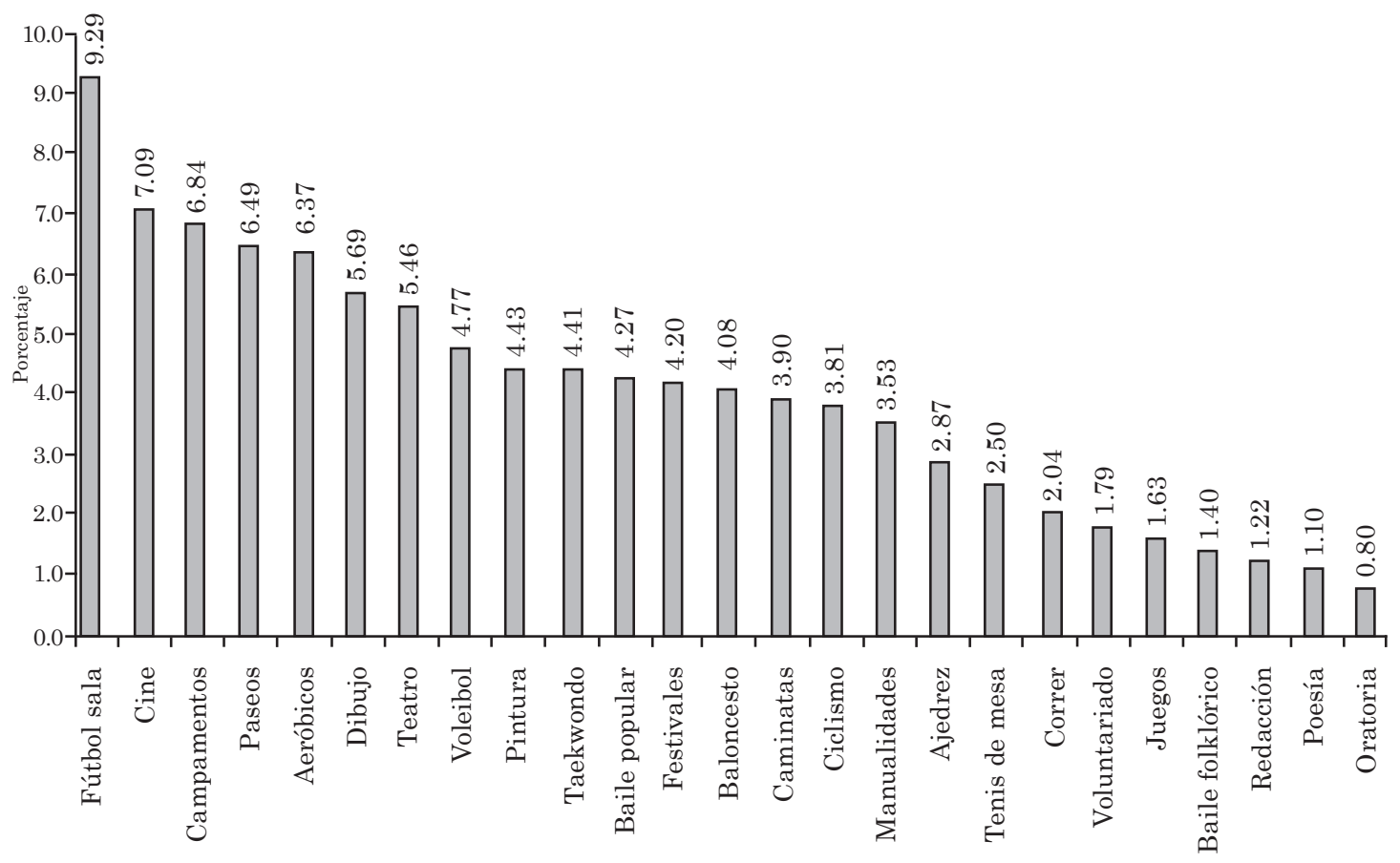

Actividades recreativas

Fuente: Elaboración propia a partir del cuestionario de actividades recreativas, UNED, enero 2006.

que las actividades preferidas por estas personas eran el deporte, paseos, el cine y las excursiones.

Así mismo, Camacho, Vargas y Corrales (1998), en su estudio con personal universitario, hallaron que el deporte era la actividad preferida, seguida por los paseos y las actividades artístico-culturales.

En cuanto a la preferencia de los hombres por el fútbol (en este caso fútbol sala), de las mujeres por los aeróbicos y de ambos sexos por el cine, concuerda con el estudio realizado por Alvarado (2000), el cual concluye que estos resultados se deben a la tradición de una cultura que es futbolística por excelencia, como sucede en Costa Rica. En relación con la escogencia realizada por las mujeres, es debido a la tendencia a buscar actividades estéticas. En lo que respecta al cine, en este estudio y en el de Alvarado es una de las actividades preferidas de la población estudiantil. En el trabajo de Alvarado fue la actividad artístico-cultural predilecta y en este proyecto fue la segunda de toda la lista.

Una razón por la cual el cine surgió como una de las actividades preferidas en la población encuestada pudo ser debido a la influencia que tiene la tecnología actualmente en la vida del ser humano. Hendel y 
Harrold (2004) mencionaban en su estudio que entre las actividades recreativas más comunes y en las que se involucra la tecnología está el uso de Internet y la música; además, recalcan que el $95 \%$ de toda la población estudiantil (colegial y universitaria) que participó en su investigación, acostumbraba alquilar películas.

Por otra parte, ambos sexos coincidieron en que las actividades recreativas de mayor frecuencia fueron las de tipo deportivo o las físicas, como resultaron ser fútbol sala y aeróbicos. Estos resultados se parecen a los de otros estudios que comprueban también el gusto por este tipo de actividades. Es el caso de Campos y Madrigal (2001), cuyos datos muestran que la mayoría del personal de las oficinas centrales de la UNED con hijos e hijas de edades entre los 4 y 12 años se interesaba en que se elaborara el programa de actividades físico-recreativas.

Así como Alvarado (2000), quien también encontró que entre las actividades realizadas en el tiempo libre por parte de estudiantes del Colegio de Santa Ana, las que causaron mayor satisfacción fueron las actividades de tipo deportivo.

\section{Importancia de las actividades recreativas para el desarrollo integral}

Otra de las consultas era con el fin de conocer si la población estudiantil consideraba importantes las actividades recreativas para el desarrollo integral del ser humano. El resultado a dicha interrogante se refleja en el siguiente gráfico.

\section{Gráfico 5}

Creencia de la población estudiantil, acerca de que las actividades recreativas, sean importantes para el desarrollo integral, en la Sede de San José de la

Universidad Estatal a Distancia

Enero 2005

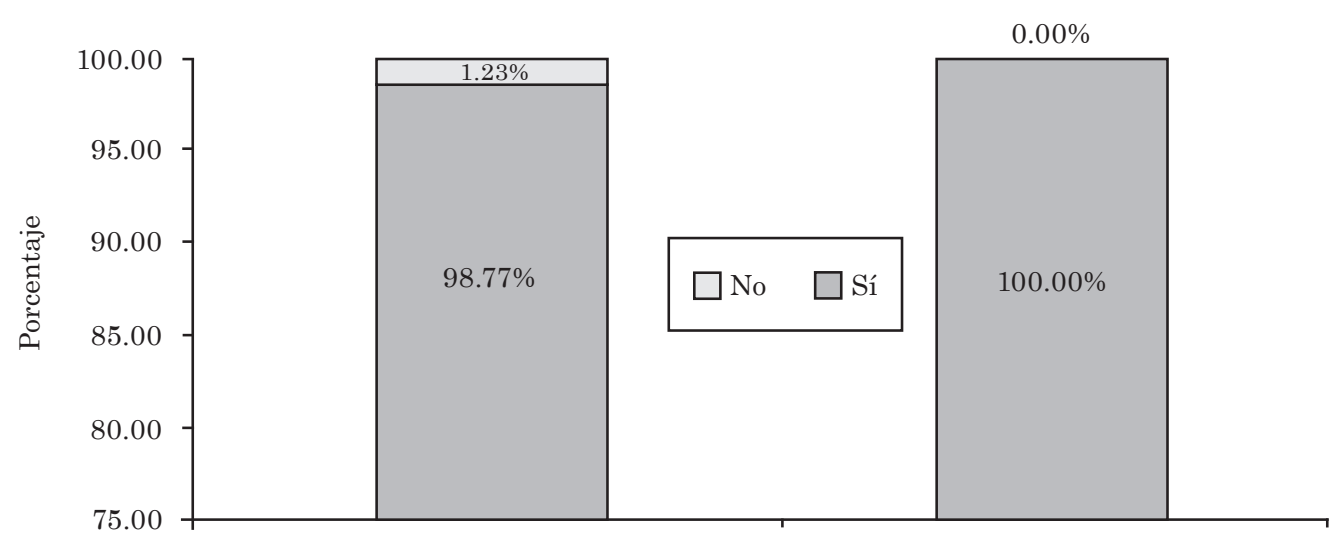

Género masculino Género Género femenino 
Los resultados de esta pregunta tres mostraron que, el $98,77 \%$ del sexo masculino (161 hombres) consideró que sí eran importantes, mientras que el 1,23\% (2 hombres) creía que no. En cuanto al sexo femenino, el 100\% (213 mujeres) contestó que sí consideraba que las actividades recreativas eran importantes para el desarrollo integral de las personas.

En lo que se refiere a los dos sexos, el 99,47\% (374 personas) respondió que sí y solo el 0,53\% (2 personas) dijeron que no creían que las actividades fueran importantes. Estos datos confirman y respaldan aun más la justificación de la propuesta, al demostrar el interés y concepto favorable de la población estudiantil, con respecto a las actividades recreativas y su criterio de considerarlas importantes para el desarrollo integral.

\section{Conclusiones}

a) De acuerdo con los resultados encontrados en el diagnóstico, se determinó que la UNED no contaba con un área de recreación; por lo tanto, fue imposible detectar en esta área el estado de varios aspectos administrativos básicos, tales como misión, visión y organigrama. Solamente se halló una normativa que hacía mención de unos grupos recreativos que, sin embargo, de acuerdo con el personal del PCD, no eran del todo funcionales. Ante estas carencias, se hizo necesario el planteamiento de una propuesta dirigida a una posible área de recreación, en la que se reforzaran y desarrollaran estos aspectos administrativos.

b) El PCD también presentó deficiencias en la falta de una misión y una visión, además de una normativa que necesitaba ser replanteada $\mathrm{y}$ un organigrama al que se le debía incorporar el área de recreación. Por lo tanto, se diseñaron varios de estos elementos administrativos, primero para el PCD y posteriormente para el área recreativa, de acuerdo con la funcionalidad para la institución a la cual va dirigida la propuesta.

c) El personal de la OBE y especialmente el del PCD se encontraban muy interesados en crear un área de recreación; incluso el personal del PCD tenía, en ese momento, en proceso el diseño de una propuesta en la que se modificaba la estructura de este programa, para subdividirlo en tres áreas: artística, deportiva y recreativa. Dicha iniciativa vino a ser apoyada con este trabajo, porque en él se crearon varios aspectos administrativos básicos que eran necesarios para la nueva estructura que pretendía incluir la propuesta del personal del PCD.

d) Los datos recolectados con el cuestionario reflejaron que la mayoría del estudiantado estaba interesado en que la Universidad realizara actividades recreativas. Además de las personas que respondieron afirmativamente a esta interrogante, la mayoría contestó que sí consideraba que estas actividades eran importantes para el desarrollo integral del ser humano, lo cual demostraba el interés por este tipo de actividades y justificaba la creación de un área recreativa que promoviera dichas prácticas.

e) En cuanto a las cinco actividades recreativas de mayor interés por parte de la población estudiantil, los resultados demostraron que, en orden de prioridad, fútbol sala, campamentos, baloncesto, cine y paseos fueron las más aclamadas por el sexo masculino. En cuanto al sexo femenino, los datos demostraron que aeróbicos, cine, teatro, campamentos y paseos fueron las más gustadas. Y a nivel general, tanto para hombres como para mujeres, el orden fue el siguiente: fútbol sala, cine, 
campamentos, paseos y aeróbicos. Estas actividades pueden ser el punto de referencia para futuros proyectos recreativos que se deseen desarrollar en el Centro Universitario de San José de la UNED.

\section{Propuesta}

A continuación se resume para cada objetivo la recomendación que la autora propone para mejorar los procesos de recreación.

Tabla 1

Resumen de los datos encontrados en el diagnóstico, con respecto al área de recreación en la Universidad Estatal a Distancia

\begin{tabular}{|c|c|c|}
\hline Objetivo & Resultado & Recomendación \\
\hline $\begin{array}{l}\text { Detectar la misión en } \\
\text { el área de recreación } \\
\text { del PCD en la UNED. }\end{array}$ & $\begin{array}{l}\text { - El área de recreación del PCD de la UNED } \\
\text { no cuenta con misión, inclusive el programa } \\
\text { no tiene misión. }\end{array}$ & $\begin{array}{l}\text { Proponer la misión para el PCD } \\
\text { de la UNED y objetivos para el } \\
\text { área recreativa. Lo anterior, de } \\
\text { acuerdo con la funcionalidad } \\
\text { adecuada para el PCD. }\end{array}$ \\
\hline $\begin{array}{l}\text { Identificar la visión en } \\
\text { el área de recreación } \\
\text { del PCD en la UNED. }\end{array}$ & $\begin{array}{l}\text { - En el PCD de la UNED no se detecta la } \\
\text { visión para el área de recreación. Incluso el } \\
\text { programa no tiene visión. }\end{array}$ & $\begin{array}{l}\text { - Recomendar la visión para el } \\
\text { PCD de la UNED y objetivos } \\
\text { para el área recreativa. Esto } \\
\text { debe estar de acuerdo con la } \\
\text { funcionalidad apta para el PCD. }\end{array}$ \\
\hline $\begin{array}{l}\text { Revisar el reglamento } \\
\text { que regula el área de } \\
\text { recreación del PCD en } \\
\text { la UNED. }\end{array}$ & $\begin{array}{l}\text { - No existe un reglamento que regule el área } \\
\text { de recreación del PCD de la UNED. } \\
\text { - Sólo hay una normativa del PCD, que se } \\
\text { refiere a los grupos culturales y deportivos } \\
\text { de la UNED. En ésta se mencionan los } \\
\text { grupos recreativos que, de acuerdo con el } \\
\text { personal del programa, se consideran poco } \\
\text { funcionales. }\end{array}$ & $\begin{array}{l}\text { - Diseñar el reglamento para el } \\
\text { PCD en el que se tome en cuenta } \\
\text { el área de recreación. }\end{array}$ \\
\hline $\begin{array}{l}\text { Identificar si existen } \\
\text { funciones específicas } \\
\text { para el área recreativa } \\
\text { del PCD de la UNED. }\end{array}$ & $\begin{array}{l}\text { - No existen funciones específicas para el } \\
\text { área de recreación. }\end{array}$ & $\begin{array}{l}\text { - Elaborar funciones específicas } \\
\text { para el personal encargado del } \\
\text { área de recreación. }\end{array}$ \\
\hline $\begin{array}{l}\text { Determinar los } \\
\text { recursos humanos, } \\
\text { materiales, } \\
\text { instalaciones y } \\
\text { presupuesto con los } \\
\text { que cuenta el PCD en } \\
\text { la UNED. }\end{array}$ & $\begin{array}{l}\text { - Recursos humanos: Cuenta con } 15 \\
\text { instructores (10 de deportes y } 5 \text { de cultura). } \\
\text { - Recursos materiales: Son administrados por } \\
\text { cada uno de los grupos representativos. } \\
\text { - Presupuesto: La Oficina de Bienestar } \\
\text { Estudiantil anualmente cuenta con: } \\
\text { ф1000000 para uso de instalaciones, } \\
\text { ф2500000 para implementos, ф3500000 } \\
\text { para viáticos. } \\
\text { - Instalaciones: Un gimnasio que se } \\
\text { encuentra en el Centro Universitario de } \\
\text { San José. Está techado, con iluminación y } \\
\text { gradería. }\end{array}$ & $\begin{array}{l}\text { - Sugerir la apertura de plazas o } \\
\text { contratos para personal en las } \\
\text { áreas de arte y de recreación. } \\
\text { - Recomendar la posibilidad } \\
\text { de beca para estudiantes que } \\
\text { ayuden en las tres áreas. } \\
\text { - Adquirir los materiales } \\
\text { necesarios para cada una de } \\
\text { las áreas, según el presupuesto } \\
\text { disponible. } \\
\text { - Coordinar el uso de las } \\
\text { instalaciones, para los proyectos } \\
\text { que deseen desarrollar las áreas. }\end{array}$ \\
\hline $\begin{array}{l}\text { Identificar las } \\
\text { actividades y proyectos } \\
\text { recreativos que } \\
\text { fomenta el PCD en la } \\
\text { UNED. }\end{array}$ & $\begin{array}{l}\text { - No se ofrecen proyectos ni actividades } \\
\text { recreativas para la población estudiantil. } \\
\text { - Actividades especiales actuales: Torneo } \\
\text { Deportivo Estudiantil y el Festival } \\
\text { Cultural. }\end{array}$ & $\begin{array}{l}\text { - Una vez que esté conformada } \\
\text { el área de recreación, sugerir } \\
\text { proyectos y actividades } \\
\text { recreativas para la población } \\
\text { estudiantil. }\end{array}$ \\
\hline
\end{tabular}


De acuerdo con los resultados obtenidos en el diagnóstico, se diseñó esta propuesta, que pretendía fortalecer la estructura organizacional del PCD de la UNED, además de crear las bases organizacionales para el área recreativa de dicho programa.

En la propuesta se reformó el organigrama. Se sugirió la misión y la visión para el programa, se proponen objetivos para cada una de las áreas que se pretendían fomentar (la deportiva, la artística y la recreativa), de acuerdo con la propuesta del personal del PCD. Por último, se diseñó un reglamento para el programa, que contempla aspectos importantes de las tres áreas sugeridas.

\section{Diseño de los aspectos elaborados en la propuesta}

\section{Organigrama}

Se realizaron varias sugerencias para el organigrama de la UNED:

a) Se modificó el nombre Programa Cultura y Deporte por Programa de Promoción del Arte, el Deporte y la Recreación (PPADR), con el fin de mantener el enfoque en las tres áreas que se pretendían establecer.

b) Se cambió el nombre de área cultural por área artística.

c) Se integraron tres áreas: la artística, la deportiva y la recreativa, las cuales vendrían a pertenecer al PPADR.

El organigrama que se propuso se puede observar en la Figura 1.

\section{Misión del Programa de Promoción del Arte, el Deporte y la Recreación} siguiente:

La misión que se propuso fue la

Contribuir con la promoción de la salud, el buen uso del tiempo libre y la formación integral de la población estudiantil de la Universidad Estatal a Distancia, mediante el planeamiento, la coordinación, la ejecución y la evaluación de proyectos y actividades en las áreas artística, deportiva y recreativa.

\section{Visión del Programa de Promoción del Arte, el Deporte y la Recreación}

La visión que se propuso fue la siguiente:

Ser un modelo de liderazgo, que facilitará el desarrollo integral del estudiantado y promoverá un estilo saludable de vida, por medio de la participación en proyectosy actividades que ofrezcan las áreas, los cuales se ajustarán a las necesidades de la población estudiantil de todos los centros universitarios de la Universidad Estatal a Distancia. Además, fortalecerá alianzas estratégicas con distintas entidades en vías de mejorar la eficacia de sus servicios, y facilitará el recurso humano, material y presupuestario, en procura del eficiente desempeño de las actividades en las áreas deportiva, artística y recreativa.

Objetivos estratégicos para cada una de las áreas

Los objetivos que se diseñaron para cada una de las áreas del PPADR fueron los siguientes:

\section{Objetivos: área artística}

1. Desarrollar en la población estudiantil la dimensión creativa del arte de una manera enriquecedora que permita el desarrollo humanista.

2. Ayudar a la población estudiantil a valorar lo lúdico, lo histórico y lo escénico como medios de expresión para alcanzar un alto nivel de desarrollo humano. 


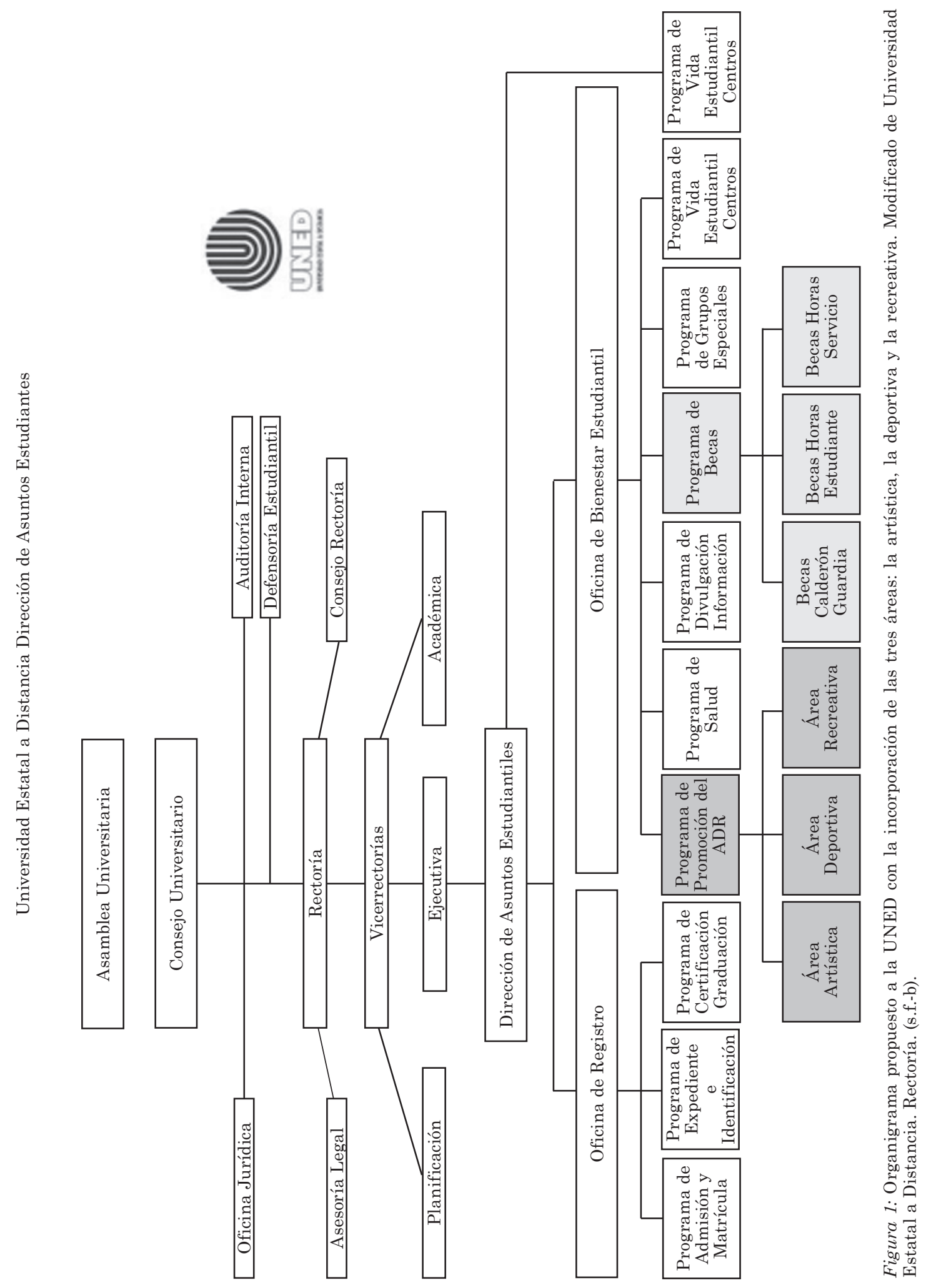


3. Incrementar el potencial artístico y fomentar el redescubrimiento de la multiculturalidad costarricense.

4. Promover la participación activa de la población estudiantil en las agrupaciones de representación artística para mostrar imágenes de la sociedad latinoamericana.

5. Contribuir en la elaboración y en la aplicación de proyectos que promueva el área de recreación.

\section{Objetivos: área deportiva}

1. Desarrollar proyectos dirigidos al deporte representativo en ámbitos como el universitario, nacional e internacional.

2. Fomentar la participación activa de la población estudiantil universitaria en el deporte representativo como un medio que propicie su formación integral y un estilo saludable de vida.

3. Brindar oportunidades a la población estudiantil para que desarrolle sus destrezas y habilidades deportivas.

4. Contribuir en la elaboración y en la aplicación de proyectos que promueva el área de recreación.

\section{Objetivos: área recreativa}

Promover proyectos y actividades recreativas en los distintos Centros universitarios de la UNED en procura de lograr una cobertura nacional, según las características, necesidades, intereses y gustos de la población de cada centro.

1. Facilitar la formación integral de la población estudiantil, por medio de la participación en los proyectos y actividades que promueva el área.

2. Difundir proyectos y actividades recreativas que fomenten un estilo saludable de vida y el buen uso del tiempo libre en la población estudiantil.

3. Trabajar en coordinación con el área deportiva y el área artística, de manera que se logre una labor interdisciplinaria en los proyectos recreativos.

4. Contribuir en la elaboración y en la aplicación de proyectos que promueva el área artística o el área deportiva.

Reglamento

El reglamento diseñado para el PPADR es el siguiente:

\section{Universidad Estatal a Distancia Vicerrectoría Ejecutiva \\ Dirección de Asuntos Estudiantiles}

\author{
Reglamento del Programa de \\ Promoción del Arte, el Deporte y la \\ Recreación \\ Capítulo I \\ Funciones
}

\section{Artículo 1}

El Programa de Promoción del Arte, el Deporte y la Recreación (PPADR) de la Dirección de Asuntos Estudiantiles depende de la Vicerrectoría Ejecutiva y su función es promover, fomentar y coadyuvar en la formación integral de la población estudiantil, por medio de los proyectos y actividades de las áreas artística, la deportiva y la recreativa de la Universidad Estatal a Distancia.

\section{Artículo 2}

La organización y el funcionamiento del Programa de Promoción del Arte, el Deporte y la Recreación están regulados directamente por las normas de este reglamento. 


\section{Articulo 3}

Las resoluciones que dicte en el ejercicio de su función el Programa de Promoción del Arte, el Deporte y la Recreación, serán apelables ante la Dirección de Asuntos Estudiantiles.

\section{Capítulo II}

De los fines

\section{Articulo 4}

Para el cumplimiento de los fines del Programa de Promoción del Arte, el Deporte y la Recreación se desarrollan las siguientes tareas:

a) Planificar, ejecutar, supervisar $y$ evaluar los proyectos y actividades artísticas, deportivas y recreativas de la Universidad Estatal a Distancia, tanto en el ámbito interno como externo. Para el cumplimiento de esta disposición se debe actuar en estrecha coordinación con las dependencias universitarias y organizaciones.

b) Elaborar y ejecutar los proyectos del Programa de Promoción del Arte, el Deporte y la Recreación.

c) Autorizar y coordinar las actividades de representación de la Universidad Estatal a Distancia, en el campo artístico y deportivo, tanto dentro como fuera del territorio nacional.

d) Autorizar y coordinar las actividades artísticas, deportivas y recreativas de la Universidad Estatal a Distancia. e) Proponer las políticas en los campos artístico, deportivo y recreativo a las instancias correspondientes.

\section{Capítulo III}

De la estructura y organización

\section{Artículo 5}

El Programa de Promoción del Arte, el Deporte y la Recreación está dirigido por una persona coordinadora del programa y está conformado por tres áreas:

a) Área artística: Comprende la participación en certámenes, festivales, torneos o cualquier otra actividad de tipo artístico, a nivel interuniversitario, dentro y fuera del territorio nacional.

b) Área deportiva: Comprende la participación en festivales, torneos, ligas, campeonatos nacionales o cualquier otra actividad de tipo deportivo, a nivel interuniversitario, dentro y fuera del territorio nacional.

c) Área recreativa: Comprende actividades físicas, deportivas, artísticas, sociales, al aire libre, cognoscitivas, turísticas, de enriquecimiento y actualización personal. Estas pueden ser realizadas a nivel interuniversitario, dentro y fuera del territorio nacional. Estas actividades son ofrecidas por medio de formatos recreativos, como clubes, grupos, competencias, concursos, paseos, excursiones, eventos especiales, clases, talleres y servicio voluntario.

\section{Artículo 6}

El Programa de Promoción del Arte, el Deporte y la Recreación cuenta con un órgano de apoyo, denominado Asociación Deportiva de la Universidad Estatal a Distancia (ADEUNED).

\section{Capítulo IV}

Responsabilidades de la persona coordinadora del Programa de Promoción del Arte, el Deporte y la Recreación

\section{Artículo 7}

Responsabilidades y obligaciones

a) Convocar, coordinar y presidir las reuniones internas del programa. 
b) Dirigir y coordinar las labores del programa para el cumplimiento de sus fines.

c) Ejecutar las resoluciones y los acuerdos tomados por las autoridades universitarias.

d) Revisar y proponer reformas ante la Oficina de Bienestar Estudiantil del presente reglamento, así como velar por el cumplimiento de este.

e) Coordinar con las instancias interuniversitarias y extrauniversitarias, actividades pertinentes a este programa.

f) Representar a la UNED en las funciones correspondientes del programa ante los organismos que sean indicados por el Consejo Universitario, la Vicerrectoría Ejecutiva y la Oficina de Bienestar Estudiantil.

g) Gestionar actividades propias al desarrollo profesional del personal del programa. h) Presentar informes que le sean solicitados por las instancias superiores respectivas.

i) Velar y supervisar el cumplimiento de normas internas de trabajo.

j) Coadyuvar en la planeación, ejecución y evaluación de los eventos artísticos, deportivos y recreativos. Asimismo, analizar las necesidades logísticas y presupuestarias de estos. Además, gestionar las instalaciones para el desarrollo de los diferentes eventos.

k) Hacer aportes relevantes relacionados con la organización de eventos deportivos, artísticos y recreativos, técnicas de entrenamiento, uso de equipo y formulación de sugerencias para su mejora.

l) Analizarperiódicaysistemáticamente a partir de la relación recursos utilizados versus resultados obtenidos los proyectos realizados por las personas subcoordinadoras de las áreas.

m) Organizar con las personas subcoordinadoras de las áreas lo correspondiente al contrato del personal, hospedaje y alimentación necesaria para los diferentes eventos. Adquirir los implementos indispensables, de acuerdo con la disponibilidad presupuestaria.

n) Participar activamente en proyectos de investigación, aportando ideas significativas para lograr los objetivos de éste.

o) Representar a la Universidad ante federaciones, asociaciones, comisiones, comités y otras organizaciones similares que realicen actividades afines con su labor.

p) Colaborar como persona experta y con conocimientos técnicos en los programas de apoyo al estudiante, como Microcampus, PADD, videoconferencia, sitio Web o la plataforma de educación virtual utilizada por la Universidad, así como en labores administrativas que se deriven de su labor y cualesquiera otras relacionadas con el puesto.

\section{Capítulo $V$ \\ De las áreas}

\section{Artículo 8}

El área artística está dirigida por una persona subcoordinadora, que tiene por funciones:

a) Elaborar, presentar y valorar los anteproyectos de presupuesto de su área ante la Coordinación del Programa de Promoción del Arte, el Deporte y la Recreación.

b) Programar, controlar y supervisar las actividades de los grupos de representación artística de la Universidad.

c) Fiscalizar la participación de los grupos artísticos representativos.

d) Coordinar y fortalecer los vínculos y demás mecanismos de interacción con el área deportiva y con el área recreativa. 
e) Presentar informes periódicos sobre la participación de los diferentes grupos de representación artística.

f) Elaborar planes a corto, mediano y largo plazo acerca de la participación de los grupos de representación artística.

g) Evaluar las acciones realizadas en los grupos de representación artística.

h) Proponer proyectos de actividades artísticas; organizar lo correspondiente al hospedaje, alimentación de los participantes, reglamentos, inauguraciones y divulgación de las actividades; velar por el pago respectivo de viáticos, y cualesquiera otras labores de similar naturaleza.

i) Coordinar el contrato del personal necesario para los diferentes eventos, como los jueces, entre otros. Adquirir los implementos indispensables, de acuerdo con la disponibilidad presupuestaria.

j) Presentar informes periódicos sobre la participación de la población universitaria en actividades artísticas.

k) Evaluar todas las acciones realizadas en el campo artístico.

l) Disponer con la Coordinación del Programa de Promoción del Arte, el Deporte y la Recreación el uso de instalaciones para el desarrollo de las actividades del área.

m) Representar a la Universidad ante federaciones, asociaciones, comisiones, comités y otras organizaciones similares que realicen actividades afines con su labor.

n) Colaborar en el planeamiento, realización y evaluación de certámenes artísticos en los festivales recreativos.

o) Proponer iniciativas y efectuar todas aquellas funciones que disponga la Coordinación del Programa de Promoción del Arte, el Deporte y la Recreación y que no estén contempladas en este reglamento.

\section{Artículo 9}

El área deportiva está dirigida por una persona subcoordinadora, que tiene por funciones:

a) Recomendar a la Coordinación del Programa de Promoción del Arte, el Deporte y la Recreación la participación de la Universidad en competencias, tanto interuniversitarias como extrauniversitarias.

b) Fiscalizar las actividades de los grupos deportivos que participan a nivel nacional e internacional.

c) Elaborar, presentar y valorar los anteproyectos de presupuesto de su área ante la Coordinación del Programa de Promoción del Arte, el Deporte y la Recreación.

d) Asesorar a los diferentes grupos deportivos representantes de la institución, así como a aquellas organizaciones internas y externas que lo soliciten.

e) Presentar informes periódicos acerca de la participación de la población universitaria en actividades deportivas.

f) Elaborar planes a corto, mediano y largo plazo acerca de la participación de los grupos deportivos.

g) Coordinar las actividades propias del deporte de competición representativo de la Universidad, tanto a nivel universitario como al de asociaciones y federaciones de representación nacional.

h) Organizar con la Coordinación del Programa de Promoción del Arte, el Deporte y la Recreación lo correspondiente al contrato del personal, hospedaje y alimentación de los participantes, reglamentos, inauguraciones, divulgación de las actividades, el pago respectivo de viáticos y cualesquiera otras labores de similar naturaleza.

i) Adquirir los implementos indispensables, de acuerdo con la disponibilidad presupuestaria. 
j) Fortalecer los vínculos y mecanismos de interacción entre el área deportiva, el área artística y la recreativa.

k) Evaluar todas las acciones realizadas por los grupos o equipos deportivos a nivel universitario y extrauniversitario.

1) Representar a la Universidad ante federaciones, asociaciones, comisiones, comités y otras organizaciones similares que realicen actividades afines con su labor.

m) Programar, controlar y supervisar, en conjunto con la persona coordinadora del área recreativa, los torneos deportivos internos.

n) Disponer con la Coordinación del Programa de Promoción del Arte, el Deporte y la Recreación el uso de instalaciones para el desarrollo de las actividades del área.

o) Proponer iniciativas y efectuar todas aquellas funciones que disponga la Coordinación del Programa de Promoción del Arte, el Deporte y la Recreación y que no estén contempladas en este reglamento.

\section{Artículo 10}

El área recreativa está dirigida por una persona subcoordinadora, que tiene por funciones:

a) Propiciar la mayor participación posible de la comunidad universitaria en las actividades recreativas que se ofrezcan.

b) Planear, programar, ejecutar, supervisar y evaluar los proyectos recreativos que se lleven a cabo con la población estudiantil de los diferentes centros universitarios de la institución.

c) Elaborar planes a corto, mediano y largo plazo de actividades recreativas internas.

d) Proponer proyectos de actividades recreativas; organizar lo correspondiente al hospedaje y alimentación de los participantes; preparar los cuadros de juego, inauguraciones y la divulgación de las actividades; velar por el pago respectivo de viáticos, y cualesquiera otras labores de similar naturaleza.

e) Coordinar el contrato del personal necesario para las diferentes actividades, como jueces, árbitros y delegados, entre otros. Así mismo, adquirir los implementos indispensables, de acuerdo con la disponibilidad presupuestaria.

f) Elaborar, presentar y valorar los anteproyectos de presupuesto de su área ante la Coordinación del Programa de Promoción del Arte, el Deporte y la Recreación.

g) Capacitar a la población estudiantil que forme parte de los grupos recreativos.

h) Asesorar a los diferentes grupos estudiantiles y de otros sectores institucionales en lo concerniente a la sana utilización del tiempo libre en actividades recreativas.

i) Presentar informes periódicos acerca de la participación de la población universitaria en actividades de recreación.

j) Coordinar y fortalecer los vínculos y mecanismos de interacción tanto con el área deportiva como con el área artística.

k) Brindar ayuda logística a los miembros de la comunidad universitaria para la organización de actividades en el campo de la recreación, formación deportiva y artística.

1) Representar a la Universidad ante federaciones, asociaciones, comisiones, comités y otras organizaciones similares que realicen actividades afines con su labor.

m) Disponer con la Coordinación del Programa de Promoción del Arte, el Deporte y la Recreación el uso de instalaciones para el desarrollo de las actividades del área. 
n) Programar, controlar y supervisar, en conjunto con la persona subcoordinadora del área deportiva, los torneos deportivos internos.

o) Propiciar la realización de certámenes artísticos en los festivales recreativos, que estimulen las prácticas artísticas.

p) Proponer iniciativas y efectuar todas aquellas funciones que disponga la Coordinación del Programa de Promoción del Arte, el Deporte y la Recreación, no contempladas en este reglamento.

\section{Capítulo VI}

Participación artística, deportiva y recreativa

\section{Artículo 11}

El Programa de Promoción del Arte, el Deporte y la Recreación genera la incursión de la población estudiantil en grupos artísticos, deportivos y recreativos.

\section{Artículo 12}

\section{Definiciones}

Grupos artísticos, deportivos y recreativos: Población estudiantil que, individual o colectivamente, se mantiene ensayando, entrenando o capacitando para participar en actividades programadas por el PPADR o para cumplir funciones establecidas por la persona subcoordinadora del área artística, la deportiva o la recreativa. Se divide en dos tipos: no permanente y permanente.

a) Grupos no permanentes: Población estudiantil que, individual o colectivamente, se integra en un grupo artístico, deportivo o recreativo por un periodo de dos cuatrimestres, bajo los controles que establece el artículo 14 y cumpliendo los requisitos del artículo 16, al igual que los deberes del artículo 17 de este reglamento. Además, dichos grupos tienen un control de asistencia establecido por el Programa de Promoción del Arte, el Deporte y la Recreación. Se convierten en grupos permanentes una vez cumplido el tiempo de dos cuatrimestres.

b) Grupos permanentes: Población estudiantil que, individual o colectivamente, forma parte de un grupo artístico, deportivo o recreativo, por un periodo mayor al de dos cuatrimestres, bajo los controles que establece el artículo 14, cumpliendo los requisitos del artículo 16 y los deberes del artículo 17 de este reglamento. Estos grupos cuentan con un control de asistencia establecido por el Programa de Promoción del Arte, el Deporte y la Recreación.

\section{Artículo 13}

\section{Becas}

a) La población estudiantil que, individual o colectivamente, forme parte de los grupos no permanentes, ya sean artísticos, deportivos o recreativos, gozará de beca $\mathrm{E}$, según lo que se establece en el artículo 24 del Reglamento de Becas para Estudiantes de la UNED.

b) El estudiantado que, individual o colectivamente se integre en los grupos permanentes, ya sean artísticos, deportivos o recreativos, gozará de beca $\mathrm{D}$, según lo dispuesto por el artículo 24 del Reglamento de Becas para Estudiantes de la UNED.

c) El alumnado que, de forma individual o colectiva, sea parte de los grupos permanentes o no permanentes, ya sean artísticos, deportivos o recreativos, gozará de beca B por un periodo posterior a su participación, siempre y cuando cumplan con los requisitos 
establecidos en el artículo 23 del Reglamento de Becas para Estudiantes de la UNED.

d) La población estudiantil que participe de manera voluntaria en las actividades recreativas que promueva el área artística, la deportiva o la recreativa no gozará de beca por participar en dichas actividades, ya que estas no tienen como objetivo la participación representativa, pero sí fomentar el buen uso del tiempo libre, los estilos de vida saludable y el desarrollo integral de sus participantes.

\section{Artículo 14}

Todos los grupos permanentes y no permanentes, ya sean artísticos, deportivos o recreativos, deben presentar los siguientes documentos:

a) Un plan de trabajo anual a la persona coordinadora del Programa de Promoción del Arte, el Deporte y la Recreación, de la Dirección de Asuntos Estudiantiles, que contemple: justificación, objetivo general, objetivos específicos, necesidades, actividades, cronograma, presupuesto y forma en que se ejecutará el trabajo, para su evaluación y aprobación.

b) Lista de estudiantes con su respectivo nombre, dos apellidos, número de cédula, y que tenga el visto bueno del Centro Universitario.

c) Un control de asistencia desglosada en forma mensual, firmada por la persona instructora a cargo del grupo y con el visto bueno de la persona que administra el Centro Universitario.

d) Un informe de labores del periodo correspondiente, el cual se entregará al finalizar cada cuatrimestre.

\section{Artículo 15}

El Programa de Promoción del Arte, el Deporte y la Recreación será la instancia técnica encargada de establecer la categorización de estos grupos y la responsable directa de velar por el cumplimiento de los requisitos establecidos en el artículo 2 de este reglamento.

El Consejo de Becas a estudiantes es el encargado de velar por que se cumpla con el reglamento vigente y con el número de estudiantes que el Programa de Becas puede cubrir.

El estudiantado tiene que cumplir con los requisitos establecidos en el capítulo IV, artículo 18 del Reglamento de Becas para Estudiantes de la UNED. En este se establece que, para conservar el derecho a disfrutar de beca, el estudiantado debe matricular y aprobar un mínimo de tres asignaturas por periodo académico. De no cumplir con alguno de estos requisitos, su beca se bajará a la categoría inmediata inferior, siempre y cuando conserve un rendimiento mínimo de dos asignaturas. Al recuperar su rendimiento académico, se le asignará la categoría que le corresponde.

\section{Artículo 16}

\section{Requisitos}

La población estudiantil que participe en grupos permanentes y no permanentes, ya sean deportivos, artísticos o recreativos, debe cumplir con ciertos requisitos para lograr su permanencia en cada grupo:

a) Asistir en representación de la UNED a las actividades que se soliciten, ya sean ensayos, entrenamientos, juegos, presentaciones o capacitaciones. Se permitirán únicamente dos ausencias motivadas por cuatrimestre, según el criterio la persona instructora, directora o entrenadora a cargo del grupo.

b) Cumplir con las funciones que le sean asignadas por la persona subcoordinadora del área artística, deportiva o recreativa. 
c) Cumplir con los requisitos académicos que se le exigen de acuerdo con el Reglamento de Becas para Estudiantes de la UNED.

d) Ser estudiante activo de la UNED.

\section{Articulo 17}

\section{Deberes}

El alumnado que participe en grupos permanentes o no permanentes, ya sean deportivos, artísticos o recreativos, tiene que cumplir con ciertos deberes, como:

a) Asistir de manera continua y participativa a los ensayos, entrenamientos, capacitaciones o presentaciones.

b) Representar a la UNED en las actividades que se programen.

c) Cumplir con las funciones que le sean asignadas por la persona coordinadora del área artística, la deportiva o la recreativa.

d) Acatar las normas establecidas en el reglamento de la actividad o competencia en la que participe.

e) Seguir los lineamientos de seguridad, orden y disciplina que se soliciten en las actividades en las que participe.

\section{Artículo 18}

La población estudiantil que se integre en grupos permanentes y no permanentes, ya sean deportivos, artísticos o recreativos, o en las actividades recreativas promovidas por el PPADR, está regida por el Reglamento de Condición Académica.

\section{Capítulo VII \\ Disposición final}

\section{Articulo 19}

Cualquier situación no contemplada en este reglamento será analizada por la Dirección de Asuntos Estudiantiles, la cual tendrá la resolución definitiva del caso.

\section{Referencias Bibliográficas}

Águila, C. (2005). El ocio en el marco sociocultural de la posmodernidad. Una aproximación desde las prácticas de los jóvenes universitarios. Apunts: Educación Física y Deportes, 81, 105.

Aguilar, J. y Meza, M. (1992). Programas de actividades físicas recreativas para hijos de los funcionarios de la UNED. (Tesis de grado sin publicar, para optar a la licenciatura en Educación y a la licenciatura en Ciencias de la Educación con énfasis en Administración Educativa). Universidad de Costa Rica, San José, Costa Rica.

Alvarado, J. (2000). Preferencias recreativas de los estudiantes del Colegio de Santa Ana. (Tesis de grado sin publicar, para optar a la licenciatura en la Enseñanza de la Educación Física). Universidad Nacional, Heredia, Costa Rica.

Ary, D., Lucy, J. y Asghar, R. (1984). Introducción a la investigación pedagógica ( $2^{\mathrm{a} e d .) . ~ M e ́ x i c o, ~ D . F .: ~ N u e v a ~ E d i t o r i a l ~}$ Interamericana S.A. de C.V.

Camacho, C., Vargas W. y Corrales, M. (1998). Las necesidades y las demandas recreativas de los trabajadores universitarios. Heredia, Costa Rica: EUNA.

Campos, R. y Madrigal, Y. (2001). Programa de atención integral del adolescente con énfasis en recreación en edades de 15 a 19 años, en los sectores Proyectos Mi Casa y Llanos Santa Lucía Oeste del área de salud de Paraíso-Cervantes. (Informe Final de la Práctica Dirigida de Graduación, para optar a la licenciatura en Enfermería). Universidad de Costa Rica, San José, Costa Rica. 
Costa Rica. Asamblea Legislativa. (1977). Ley de creación de la Universidad Estatal a Distancia. $N^{o}$ 6044. Recuperado el 7 de diciembre de 2005 de http://www.uned.ac.cr

Costa Rica. Ministerio de Planificación Nacional y Política Económica (MIDEPLAN), y Sistema de Indicadores sobre Desarrollo Sostenible (SIDES). (2005). Sistema educativo costarricense: Matrícula total y porcentaje de matrícula pública y urbana. Recuperado el 3 de enero de 2006 de http:// www.mideplan.go.cr/Sides/social/ 0402.htm

Gómez, M. y Ruiz, F. (2003). Evolución de la práctica deportiva de la comunidad universitaria almeriense y su influencia en el deporte municipal. Efdeportes, 9(59). Recuperado el 19 de diciembre de 2005 de http://www. efdeportes.com/efd59/almeria.htm

Hendel, D. y Harrold, R. (2004). Undergraduate student leisure interests over three decades. College Student Journal, 38(4), 557-568.

Hernández, M. y Gallardo, L. (1994). Marco conceptual: Las actividades deportivorecreativas. Apunts: Educación Física y Deportes, 37, 58-67.

Hernández, R., Fernández, C., y Baptista, P. (2003). Metodología de la investigación ( $3^{\mathrm{a}}$ ed.). México: McGraw-Hill/Interamericana Editores, S. A. de C. V.

Kraus, R. (1990). Recreation and leisure in modern society ( $4^{\mathrm{a}}$. ed.). Estados Unidos: HarperCollins Publishers.

Loy, M. (1975). Estudio sobre algunos aspectos de la recreación y su situación en la ciudad de San José de Costa Rica. (Tesis de grado sin publicar, para optar a la licenciatura en Trabajo Social). Universidad de Costa Rica, San José, Costa Rica.

Mathieu, W. (1993). La educación física, el deporte y la recreación en la formulación de politicas de atención integral a la salud del costarricense. (Tesis de grado sin publicar, para optar a la maestría en Salud Pública). Universidad de Costa Rica, San José, Costa Rica.

Morales, J. (1994). Propuesta de un plan recreativo para los jubilados de la tercera edad del Colegio de Contadores Privados de Costa Rica. (Tesis de grado sin publicar, para optar a la licenciatura en Educación Física). Universidad de Costa Rica, San José, Costa Rica.

Organización Internacional del Trabajo. (2005). Conferencia Internacional del Trabajo. Nonagésima tercera reunión, 31 de mayo al 16 de junio de 2005, Ginebra, Suiza. Rcuperado el 3 de enero de 2006 de http://wwwilomirror.cornell.edu/public/spanish/ standards/relm/ilc/ilc93/index.htm

Roque, R. (1999). Modelo teórico del ocio. Una propuesta de interpretación conceptual. En R. Roque, D. Villalobos, J. Rodríguez, R. Bustamante, A. Mosquera y A. Torres . (Eds.), Ocio, tiempo libre y recreación (pp. 22-26). San José, Costa Rica: ICODER.

Rossman, J. (1983). Participant satisfaction with employee recreation. Journal of Physical Education and Dance, 15(10), 60-62.

Salazar, C. G. (1997). Percepción de la Recreación y las barreras que impiden participar en ella. En Universidad de Costa Rica, Facultad de Educación, Escuela de Educación Física y Deportes (Eds.), Memoria del IV 
Simposio Internacional en Ciencias del Deporte, el Ejercicio y la Salud (pp. 77-85). San José, Costa Rica.

Salazar, C. G. (2007). Recreación. (1ª ed.). Costa Rica: Editorial UCR.

Stevenson, H. y Stigler, J. (1999). ¿Por qué los escolares de Asia Oriental tienen alto rendimiento académico? Reproducción de los capítulos 7, 8 y 9 del libro "The learning, gap. Why our schools are failing and what we can learn from japanese and chinese education". Estudios Públicos, 76, 297-357. Recuperado el 3 de enero de 2006 de http://www.gestionescolar.d/ articles92464_estudiantesasia.pdf

Universidad Estatal a Distancia. Oficina de Bienestar Estudiantil, Programa Cultura y Deporte. (1999). Normativa para los grupos culturales y deportivos [desplegable]. Costa Rica: EUNED.

Universidad Estatal a Distancia. Rectoría. (s.f.-a). Misión de la UNED. Recuperdo el 18 de noviembre de 2005, de http:// www.uned.ac.cr/rectoria/mision.htm
Universidad Estatal a Distancia. Rectoría. (s.f.-b). Organigrama de la UNED. Recuperado el 18 de noviembre de 2005 de http://www.uned.ac.cr/ rectoria/organigra.htm

Universidad Estatal a Distancia. Rectoría. (s.f.-c). Visión de la UNED. Recuperado el 18 de noviembre de 2005 de http://www.uned.ac.cr/rectoria/vision.htm

Universidad Nacional Autónoma de México, Dirección General de Actividades Deportivas y Recreativas. (1996). Memoria UNAM. Recuperado el 5 de diciembre de 2005 de http:// dgedi.estadistica.unam.mx/memo96/ dgadyr.htm

Villalobos, D. (2001). Actividad física, deporte y recreación como medios de prevención y tratamiento de la violencia intrafamiliar. En R. Roque, D. Villalobos, J. Rodríguez, R. Bustamante, A. Mosquera y A. Torres (Eds.). Ocio, tiempo libre y recreación (pp. 113-117). San José, Costa Rica: ICODER. 